\title{
What is Musical Meaning? Theorizing Music as Performative Utterance *
}

\author{
Andrew J. Chung
}

NOTE: The examples for the (text-only) PDF version of this item are available online at: http://www.mtosmt.org/issues/mto.19.25.1/mto.19.25.1.chung.php

KEYWORDS: musical meaning, semiotics, J. L. Austin, performative utterance, speech-act theory, philosophy of language, experimental music

ABSTRACT: In this article, I theorize a new conception of musical meaning, based on J. L. Austin's theory of performative utterances in his treatise How to Do Things with Words. Austin theorizes language meaning pragmatically: he highlights the manifold ways language performs actions and is used to "do things" in praxis. Austin thereby suggests a new theoretic center for language meaning, an implication largely developed by others after his death. This article theorizes an analogous position that locates musical meaning in the use of music "to do things," which may include performing actions such as reference and disclosure, but also includes, in a theoretically rigorous fashion, a manifold of other semiotic actions performed by music to apply pressure to its contexts of audition. I argue that while many questions have been asked about meanings of particular examples of music, a more fundamental question has not been addressed adequately: what does meaning mean? Studies of musical meaning, I argue, have systematically undertheorized the ways in which music, as interpretable utterance, can create, transform, maintain, and destroy aspects of the world in which it participates. They have largely presumed that the basic units of sense when it comes to questions of musical meaning consist of various messages, indexes, and references encoded into musical sound and signifiers. Instead, I argue that a considerably more robust analytic takes the basic units of sense to be the various acts that music (in being something interpretable) performs or enacts within its social/situational contexts of occurrence. Ultimately, this article exposes and challenges a deep-seated Western bias towards equating meaning with forms of reference, representation, and disclosure. Through the "performative" theory of musical utterance as efficacious action, it proposes a unified theory of musical meaning that eliminates the gap between musical reference, on the one hand, and musical effects, on the other. It offers a way to understand musical meaning in ways that are deeply contextual (both socially and structurally): imbricated with the human practices that not only produce music but are produced by it in the face of its communicative capacities. I build theoretically with the help of various examples drawn largely from tonal repertoires, and I follow with lengthier analytical vignettes focused on experimental twentieth and twenty-first century works.

DOI: $10.30535 / \mathrm{mto} .25 .1 .2$

Volume 25, Number 1, March 2019

Copyright (๑) 2019 Society for Music Theory 


\section{Preliminaries}

[0.1.1] While music theorists and musicologists have asked many questions about the meanings found in particular pieces of music, and how they got there, less thoroughly have scholars interrogated what it is for music to be meaningful. This article develops such an account, based upon theories of language efficacy offered by ordinary language philosophy - in particular, J. L. Austin's idea of performative utterances ([1962] 1975). Via this thought, I argue that musical meaning is best understood not as a matter of how musical structures, objects, or processes represent, refer to, or otherwise map onto, either extramusical or music-internal correlates. It is better understood as a matter of how music, as something we can interpret, is used to generate effects and to perform meaningful actions with meaningful consequences, to which we find ways to comport our listening, performing, or otherwise "musicking" selves, to use a coinage of Christopher Small's. ${ }^{(1)}$ This way of thinking posits that the categories we frequently appeal to when discussing musical meaning-expression, disclosure, referentiality, symbolism, signification, and the like-are limited in their adequacy to address musical meaning. These are simply a few ways to negotiate the pressures applied to us by the communicative efficacy and actional character of music's "utterances," albeit historically and discursively important ones. ${ }^{(2)}$ A more robust position is to take the acts that music performs within the contexts in which it occurs as the basic units of sense for the inquiry into musical meaning. Considering theories of Austin's performative language theory, I argue that the linguistic turn in musical studies - and more recent disavowals of it - need to be rethought, and I propose that the concept of music as performative utterance supplies the condition of possibility for music's meaningfulness.

[0.1.2] The task of this essay is not to make metaphysical or ontological pronouncements claiming that music is utterance, that it is communication, or that it is language-like, and it certainly does not endorse the notion that music is reducible to or exhausted by its meaning. Instead, this essay has the more modest goal of defending an account of what exactly is taking place if we choose to construe music as meaningful, when we find it to be communicative, when we decide to consider it as utterance, and when we endorse some version of the idea that music gains richness and contour through its meanings (without denying that rich surpluses exceed them). The difference between these two sorts of claims is that the metaphysical/ontological claim would profess to be true regardless of whether or not one accepts the music-language analogy and the model of music as communication or utterance. Yet, for music to be able to mean, communicate, or utter at all requires a cooperation on our part, to hear and interpret it as such. The metaphysical/ontological claim is incoherent: a signal, such as a beep from a household appliance, is not a signal in virtue of some sort of deep, ultimate identity we can appeal to-it can only function as a signal for us if we are disposed to relate to it in that way.

[0.1.3] It is certainly far from universally accepted that verbal utterance and linguistic communication are universally valid, incontrovertible models for understanding music. Indeed, rejecting these models seems to be increasingly popular, with numerous examples of recent scholarship abandoning music-language parallels along with notions of "meaning" and semiosis. I want to return to that fork in the road to rethink what was jettisoned there when Joseph Kerman's (1980) disciplinary injunction towards criticism, hermeneutics, and meaning was unshouldered, and to consider what may never have been fully picked up at all. I sympathize with the desire to question the long-standing privilege of representation in humanistic thought, but I remain wary of the pendulum's swing in the opposite direction towards the nondiscursive, non-semiotic aspects of music and its ineffable sensuosity. The arc of a pendulum, of course, passes through a territory between the vertices of its swing: at the bottom of the pendulum's arc is where it has the most momentum. My goal is to theorize this in-between and to interrogate the impetus to "get out" of the semiotic (or to dig our heels into it). Clarifying a more robust center from which to evaluate the music-language/utterance/communication analogy will enable us to accept or reject that model on more reflective grounds.

[0.1.4] Extrapolating from Austin's work provides a theory of musical meaning based on an intuitively familiar idea: music performs actions and has effects for its listeners. Austin's performative language theory occasions a deeper consideration of the "performative" as an analytic rubric, a consideration that extends beyond more familiar applications of the term, which 
include the study of music in performance, musical performers, and the musical performance network. It clarifies distinctions between meanings that can be assimilated to music's representational capacities, and ones that, strictly speaking, cannot. It makes precise distinctions between the acts that music performs and the effects it can lead to and theorizes the conditions under which these can arise.

[0.1.5] Below, I will first demonstrate some theoretical lacunae to which prevailing conceptions of musical meaning fall victim, before summarizing major points and implications of Austinian theory and ordinary language philosophy more broadly with a diversity of basic musical examples. I will analyze the entangled multiplicity of ways in which the terms "performative" and "performativity" have been construed before offering a set of maxims about musical meaning based on Austin's theorization of language efficacy. Finally, I will offer brief analytical vignettes of pieces by European composers Michael Beil and Peter Ablinger to demonstrate a few ways in which conceptual tools drawn from Austinian theory and ordinary language philosophy might provide analytic points of entry into music that places conceptual roadblocks before standard hermeneutic circumspection and forms of score-based analysis. It will be impossible to treat this topic comprehensively in a single article, so the goal here will be to simply motivate and explain some resources for more powerfully thinking musical meaning, thereby suggesting further avenues for application that will have to go underexplored.

[0.1.6] For the purposes of this article, music will not be taken as an abstract entity. It will be considered in terms of real instances of its taking place, or real acts of its being imagined to take place. I aim to define "musical sound" in great generality without erecting any categorically exclusionary borders as to what does and does not count as music. My particular training and expertise lead me frequently to discuss works and performances. The Western work concept will be implicit across much of the discussion. However, I by no means endorse the view that music is a universal, transhistorical doing answerable always to Western ideas of works, and I reject the idea that it is a practice that all cultures (either across the world or across time) construe in the same way according to the same definitional constraints. The extent of music's separateness from other practices - such as language, science, exhibition artwork, dance, theater, ritual/theological practices, etc. - has always been up for contestation, and the lines are drawn differently depending on which cultures or authorities one consults on this matter. What I do maintain is that any occurrence of real or imagined musical sound considered as such, however defined, is a doing (rather than, strictly, a thing) that interfaces with the goals, concerns, and activities of its practitioners. The goal of this essay is to theorize robustly how meaning comes from that doing. First, however, it is necessary to clarify the shortcomings of prevailing orientations towards musical meaning.

\subsection{Meaning-as-Mapping}

[1.1.1] In recent years, it has become increasingly common among some music scholars to take their leave of ideas of musical meaning, music-language parallels, and the investigation of music in view of its semiotic aspects. Clemens Risi writes: “Using the theories of performativity as a starting point, a shift of the theoretical and analytical perspectives takes place: the transition from representation to presence, from referentiality to materiality, from symbolic sense and semiotic meaning to experience and sensual feeling" (2011, 285). In Sensing Sound, Nina Eidsheim remarks in a similar hue: "Trapping music in the limited definition that follows from [what she calls] the figure of sound (that is, a stable signifier pointing to a static signified) constitutes an unethical relationship to music. According to my definition, having an ethical relationship to music means . . . realizing that music consists not only of inanimate materials, but also of the materiality that is the human body" $(2015,21){ }^{(3)}$ These are strong claims against investigating categories of musical meaning. In Risi's view, these categories pertaining to meaning are buttressed by shopworn and dissatisfyingly abstract perspectives. In Eidsheim's view, their very use in our discourses might enact a disfiguring and unethical violence to the sensuous fact of music's materiality and embodiment, siphoning our attention away from the ways in which sonic vibrations produce material effects on others. ${ }^{(4)}$ 
[1.1.2] Other scholars, however, continue to embrace the study of music's parallels to language and its signifying character, as the enthusiastic development of topic-theoretic research, studies of musical narrativity, and continued hermeneutic work attests. This antagonism around the axis of the linguistic turn reflects recent trends in humanistic thought broadly. As literary theorist Toril Moi puts it, "a number of new theory formations - affect theory, new materialism, posthumanism, and so on-began their struggle to throw off the yoke of the 'linguistic turn,'" in contrast to those who continue to seek meaning and signification in literature and culture $(2017,17) .{ }^{(5)}$

[1.1.3] Both styles of thought schematized above, either in moods skeptical towards or welcoming of the linguistic turn, actually share a deep commonality. Both tend to construe forms of reference, representation, and disclosure (structured in the image of the signifier-signified relation), to be paradigmatic of meaning as such. ${ }^{(6)}$ This paradigm, which I will call the ideology of meaning-asmapping, can be observed in two forms. One form involves maneuvers like construing musical meaning in terms of expressive contents that music maps to, mapping music's formal features to a narrative, identifying the disclosure of philosophical commitments in musical sound, and so forth. Diverse scholarly programs invoke iterations of this structure as a foundational premise even as they look far beyond it: from Adorno's (1978) idea of social exigencies being expressed immanently in music, ${ }^{(7)}$ to the criticism and hermeneutics that Joseph Kerman (1980) called for some years later; from studies of musical narrativity and topic theory, even to cognitive metaphor theories of musical gesture.

[1.1.4] Another form of this paradigm posits meaning-as-mapping as the underlying framework in order to neutralize it. Some scholars motivate materialist, affective, and "performative" paradigms by elevating their virtues above those of representation, reference, and semiotic meaning. Leo Treitler describes the related view that "music is said to be otherworldly and inscrutable, to demand exegesis and defy it. In the very posing of the question of meaning there is an implication of its pointlessness, of the impossibility of finding answers" $(2011,4)$. Advancing the idea that music is a system of empty or floating signifiers without signifieds, or a sensuous medium that constantly exceeds signification is, however, still to construe the signifier-signified mapping as the essence of musical and linguistic signs. ${ }^{(8)}$ This view takes the declarative, propositional semantics of assertions as the essence of language meaning, adding the proviso that music can only ever approximate denotative or connotative functions of language, if it can at all. Within this logic, one of the foundational assumptions is, to ventriloquize Moi, "that language [or music] as such either 'refers' or 'fails to refer.' It is as if 'language' [or music] just sits there as a huge, lumbering structure that constantly refers, or fails to" $(2017,121)$.

[1.1.5] Meaning-as-mapping, in other words, is a framework in which the basic units of sense are referential, symbolic, or semantic relations. Granted, this idea is typically heavily qualified. Lawrence Kramer writes: "What is objectively 'present' in the work . . . is not a specific meaning but the availability or potentiality of meanings" $(2002,118)$. Carolyn Abbate $(2004,516)$ looks to Jankélévitch to affirm that musical meaning in its pluripotentiality arises in the messy and contingent interface between listening subject and sounding music, not in some sort of immanent encoding. ${ }^{(9)}$ But these are still affirmations of meaning-as-mapping that supplement meaning-asmapping with additional structure. This framework invokes a dichotomous logic that separates what music "says" or "tells" from what it does. ${ }^{(10)}$

[1.1.6] This essay develops another path altogether, inspired in part by philosopher Ludwig Wittgenstein's strategy of rejecting both the embrace of and turn away from an idea on the grounds that both hold in common a limited picture of the idea in question (see Moi 2017, 12). Leonard Meyer isolates the crux of this limited picture of musical meaning-as-mapping: "The debates as to what music communicates have centered around the question of whether music can designate, depict, or otherwise communicate referential concepts, images, experiences and emotional states" $(1956,32)$. If we presume this picture of music's meaning and communicative potential as a given fact, certain conceptual problems arise.

\subsection{The Problem of Musical Meaning}


[1.2.1] Meyer makes a startling claim: "Because it has not appeared problematical to them, referentialists have not as a rule explicitly considered the problem of musical meaning" $(1956,33)$.

(11) I take Meyer to be saying that a variety of questions have been asked about how music refers to the world, while certain more fundamental questions remain to be addressed. In order to advance any claims about the meanings we find in music, what is first required is an understanding of meaning. The concept of meaning acts as a handy tool for the challenge of uncovering meanings from often recalcitrant and always semantically underdetermined works and musical phenomena. (12) Any subsequent arguments, whether for or against a notion of musical meaning outside of itself (or at all), therefore always proceed from certain presumptions concerning what meaning means - what it is for something to mean, what it means for music to say something, how we ask about meaning, and even how we might quarantine musical meaning and cast it off from our concerns. Thus, inquiries frequently race past a yet more fundamental question: What is it for music to have meaning? This derives from a question of greater generality: What does meaning mean ${ }^{(13)}$

[1.2.2] These are vexed questions. To mean serves a sort of copular function in this thinking: too basic and fundamental to grasp analytically. Meyer lamented "a lack of clarity as to the nature and definition of meaning itself" (32), and an element of the difficulty he points out stems from the fact that a preunderstanding of meaning is the condition of possibility for setting into motion any questions about meaning to begin with. There is a structural problem to the question of "what meaning means" and others like it. As philosopher Mary-Jane Rubenstein explains, the thing which "stands under every investigation is precisely what investigation cannot understand" (2012, 2). The question "what does 'meaning' mean?" makes significant presumptions at the instant it is asked because its very form is structured according to a referential logic that seeks the ["what"] that maps to [the concept of meaning] through the relation designated by the verb "to mean." The referential logic and mapping-based form of the question make it difficult to separate referential mapping from meaning as such. ${ }^{(14)}$

[1.2.3] Wittgenstein once wrote: "A picture [of what meaning consists in] held us captive. And we couldn't get outside it, for it lay in our language, and language seemed only to repeat it to us inexorably" ([1953] 1958, §115). That is, it is impossible to approach the topic of musical meaning in scholarly discourse innocent of preconceptions about meaning. Because these discourses take place in language (albeit language about non-language), we will genuinely find ourselves running up against connotations that adhere viscously to a vocabulary more suited to received notions. We see straight past our preconceptions regarding "meaning" and related terms because we are accustomed to their stickiness and hence they resist becoming apparent. This amounts to a forgetting of meaning as such. Recognizing this forgetting, however, marks an opportunity to better see the foundational assumptions and presuppositions we make about meaning and how we ask about it, to see these naturalized habits as ideological, to see their distorting effects - and to see alternatives. ${ }^{(15)}$

[1.2.4] Let me adapt a metaphor from Heidegger's thinking. Musical meaning is a tree that grows leaves such as New-Musicology-style hermeneutics, post-Nattiez music semiotics, 18th-century musical topic theory, accounts of gestural meaning and narrativity - and even the turn towards music's sensuous ineffability, away from the investigation of meaning. We can learn something of the tree from sampling its leaves. But beneath lies a soil from which the tree nourishes itself-a soil that remains concealed and buried when we approach from the canopy, branches, bark, and roots. We cannot properly assay this soil until we have a way of pushing past meaning-as-mapping.

\subsection{Ordinary Language Philosophy: Meaning-as-Use}

[2.1.1] Oxford philosopher of language J. L. Austin theorized an alternative to meaning-asmapping, arguing for meaning-as-use in his treatise, How to Do Things with Words ([1962] 1975), from which developed the concepts of speech-acts and performative utterance. His work shares certain deep affinities with the work of Wittgenstein in Philosophical Investigations ([1953] 1958). They develop versions of the radical position that meaning is not primarily about mappings between signifiers and signifieds, but that it is fundamentally about the uses, effects, and actions that utterances are 
recruited to perform, in concert with the care we exercise over how they affect our goals, concerns, and activities we are involved with. These are pillars of what is now known as ordinary language philosophy: a philosophy of language that derives its insights not from analysis of language's abstract structures, but from the ways language is actually deployed in daily life.

[2.1.2] Ordinary language philosophy challenges the doxa that words and sentences "simply have a given core meaning," as Moi $(2017,40)$ puts it, showing how the circumstances of use imbue language with meaning in a myriad of ways. This insight implies that the primary distinction recognized between music and language-that language involves one-to-one mappings between signifier and signified while music cannot-relies upon a characterization of language that language itself regularly contravenes. Ordinary language philosophy suggests ways to construe the music-language metaphor in ways that are not hampered by the shortcomings of this picture of language meaning. An analogous conception of musical meaning neither rejects nor invalidates insights based on meaning-as-mapping, but simply draws a wider circle around them, logically subsuming them.

[2.1.3] By theorizing the communicative functions of music-as-utterance using ordinary language philosophy's concept of performative utterance, I propose that ideas of musical effects and musical signs are not incommensurable or antinomic. Music's efficacy might have precisely to do with ideas of musical meaning and the semiotic, language-character of music, not just its sensuous immediacy. I propose that what counts in a discourse on musical meaning might concern much more than, for instance, the disclosure of narratives within sonata movements, or how a composition's harmonic devices might comment on the political circumstances of its era. Musical meaning is underwritten by praxis: how we use music to do things and how we comport ourselves to the pressures that musical meaning applies to our goals, concerns, and activities.

[2.1.4] A number of predecessors in the field directly inspire the Austinian focus of this work. Ethnomusicologists Judith Kubicki (1999), Deborah Wong (2001), and Jim Sykes (2018) invoke Austinian theory to analyze ritual efficacies of Taizé liturgical singing, courtly Thai Buddhist performances, and Sri Lankan berava music, respectively. ${ }^{(16)}$ Philip Rupprecht (2001) analyzes musical settings of speech-acts in Britten's libretti. Justin London (1996) and music sociologist Tia DeNora (1986) both suggest that the music-language metaphor can be made more robust by expanding beyond semantic theories to consider pragmatic theories of speech-acts. ${ }^{(17)}$ Austin's work can be generalized for musical study, towards approaches including and beyond music-text relations, targeted approaches to fieldwork, and hermeneutic claims. Ultimately, without a usetheoretic perspective on musical meaning, we do not possess a framework adequate to the notion that music can even mean anything at all, except in a limited sense.

[2.1.5] The theoretical account of the grounds of musical meaning outlined below will ultimately resemble what philosophers of language call a "foundational theory" of meaning: not a theory devoted to accounting for any particular meanings that we may find and how they got there (a "semantic theory"), but one that provides an account of the underpinnings in virtue of which there can be meaning in the first place. ${ }^{(18)}$ As such, this project does not amount to the construction of a machine that processes musical works or performances (or fragments of them) and extracts nuggets of meaning. It offers little in the way of pronouncements on method or musical analysis. Instead, it will provide a foundational account of what it is to construe music as meaningful, will provide a robust theoretical account of music's communicative actions and efficacies, and will advance an argument that will enable us to consider what music "says" and what it "does" in a unified fashion.

\subsection{Austin's Speech-Act Theory within Ordinary Language Philosophy}

[2.2.1] Austin's theoretical project in his seminal treatise, How to Do Things with Words, centers around a particular historical corrective: "It was for too long the assumption of philosophers that the business of a 'statement' can only be to 'describe' some state of affairs, or to 'state some fact', which it must do either truly or falsely" ([1962] 1975, 1). Somewhat earlier, Wittgenstein pointed out similarly that we have fixated upon dealing with meaning "as if meaning were an aura the word brings along with it and retains in every kind of use" ([1953] 1958, §117). Austin refers to this 
tendency as a sort of "descriptive fallacy" ([1962] 1975, 3) originating in a fixation upon what he calls the constative dimension of utterance: what utterance discloses and how it references states of affairs in the world. But, he observes, "it has come to be commonly held that many utterances which look like statements are either not intended at all, or only intended in part, to record or impart straightforward information about the facts" ([1962] 1975, 2). That is, declarative statements typically do more than simply declaring or stating. They also possess efficacy and they can do things, "prescribing conduct or influencing it in special ways" ([1962] 1975, 3).

[2.2.2] Austin refers to this dimension - in which we "do things with words" and create effects with them - as the "performative" dimension of utterance, in contrast to its constative dimension. His fundamental point is that language not only represents or discloses the world, but that it also has a (per)formative effect in creating, destroying, transforming, or maintaining aspects of reality. Preliminarily, Austin gives the following examples of performative utterances or speech-acts: ${ }^{(19)}$

1. Saying "I $d o^{\prime \prime}$ at one's wedding to effect the marriage, rather than to merely predicate about it.

2. Saying "I name this ship the Queen Elizabeth" as when smashing a bottle of champagne against the hull of the vessel to perform an act of naming/christening.

3. Writing "I give and bequeath my watch to my brother" in one's last will and testament to perform the act of bequeathing.

4. Saying "I bet you sixpence it will rain tomorrow" to actually make the bet and not merely describe it (Austin [1962] 1975, 5).

[2.2.3] These examples illustrate four different acts that four specific utterances can perform, acts of: committing oneself in marriage, naming a ship, legally bequeathing a possession, and betting on an event. The particular acts that a sentence performs or is construed to perform are called the illocutionary forces or acts of a sentence: literally, what specific thing is done in virtue of a locution's being uttered (il-locution). Promisingly for this study, linguist Manfred Bierwisch recognized: "There are many non-verbal acts having the same illocutionary force . . . as certain corresponding speech-acts" $(1980,3) .{ }^{(20)}$ Austin names five classes of illocutionary acts that utterances can perform, which we can examine for present purposes by way of some basic musical examples. I use Austin's taxonomy (rather than others which have since been proposed) not because his stands as the final word on grouping different illocutionary acts into distinct families, nor because their names are particularly important, but simply to illustrate a variety of ways in which speech-act theory can translate into construing music as utterance.

[2.2.4] Illocutions of Austin's first category are called verdictives, acts in which utterance is used to place judgment upon phenomena. One example of a musical verdictive might be in the quotation of Wagnerian voice-leading and seventh-chord syntax in Debussy's "Golliwog's Cakewalk," and the "smirking" jocular figures that follow (Example 1). Debussy juxtaposes the gravitas of the Tristan quotation against light figurations inspired by an American vernacular dance. This juxtaposition is an example of what Robert Hatten (2004) would refer to as a trope, combining two basic meaningful units into a more sophisticated complex. This juxtaposition amounts perhaps to an act of burlesquing: causing serious material to appear absurd or exaggerated through ironic or parodic juxtaposition with comic material (recall that Debussy's performance markings hyperbolically read "avec une grande émotion" here). Whether or not Debussy's quotation was intended as a mockery of Tristan and Isolde or was meant as a value judgment upon it, the conditions under which we interpret it include our contextual enculturation into practices of irony and parody presumably shared by the composer in his context. This trope of the Wagner quotation (initially at the pc-level of the original Tristan chord) and the smirking figures, by virtue of the norms of irony and parody, can plausibly be interpreted as an act of making light of the Tristan quotation. The verdictive act performed in this quotation brings with it the performance other simultaneous actsfor instance, quoting, depicting, or reminding audiences of Richard Wagner. Moreover, any given performance of the piece may further accomplish a variety of situationally contingent acts.

[2.2.5] Another of Austin's categories of illocutionary acts is the category of commissives, acts in which utterance is used to commit to certain courses of action. In this connection, we might think of a simple dominant pedal in Western tonal syntax. It sets up a psychological expectation further 
buttressed by its syntactical function and its phrase-rhythmic weight, thereby committing to certain courses of metric, harmonic, and voice-leading action. It gives something like a promise to resolve in a certain way at a certain time-a promise which may be kept, deferred, or broken (though a lack of expected resolution is hardly the moral equivalent of a broken promise). The depiction of longing, so commonly attributed to Tristan and Isolde, depends precisely on the commissive, promissory force of the many dominants it approaches over its course. We might say that the Tristan Prelude's repeated acts of withholding resolution to local tonics accumulate. They collectively perform a higher-order act of committing to an idiom of tonic evasion. The Prelude's mm. 15-23 is given in Example 2a. Listening from the beginning of the prelude, consider how disjunctive it would be for the 4-3 suspension onto dominant-functioning B major at $\mathrm{m}$. 23 to resolve "properly" to E minor before taking off in a chromatic ascent into m. 24, as recomposed in Example $\mathbf{2 b}$. The bizarrely hollow quality of this resolution is at once a recognition of an act of committing to an idiom in the first twenty-two measures, and the disavowal of that commitment at m. 23.

[2.2.6] Closely related to commissives are what Austin calls exercitives, acts in which utterance is used to exercise power or influence and avow the consequences of that exercise of influence. Austin further glosses exercitive acts as "decision[s] that something is to be so, as distinct from judgment[s] that it is so" ([1962] 1975, 155). In this connection, we might return to the Tristan Prelude. Its continual evasions of local tonics - in favor of transposed approaches to the dominant, deceptive resolutions, tonal non-sequiturs to foreign dominants and the like-function to normalize the cadence-avoiding idiom of the opera. In these evasions of tonic arrival, there is a decision that a certain harmonic and contrapuntal state of affairs is to be so for the duration of the work (it inaugurates a condition of longing for constantly-evaded tonics), and that a syntactical state of affairs governed by traditional diatonic procedures of phrase structuration/succession was not to be so. For further illustrations, we might think of more functional uses of music, like the use of military marches to coordinate troop movements and footfall, or how the playing of reveille acts as a signal at countless sleepaway camps to start one's day. Note here that whether one is evaluating concert music in ways that theorists and musicologists are accustomed to doing, or evaluating "functional" musics, the Austinian perspective partially flattens this distinction and describes both in terms of music being used to accomplish various things and as taking place against the backdrop of our goals, activities, and concerns.

[2.2.7] Verdictives, commissives, and exercitives are followed by what Austin calls behabitives, acts in which utterance is used to accomplish certain social functions in reaction to the behavior of others as in thanking, congratulating, welcoming, and so forth. As simple examples, we could cite as musical behabitives the three pieces Elliott Carter wrote for birthdays of Pierre Boulez: Esprit Rude/Esprit Doux I (1985, flute and clarinet), Esprit Rude/Esprit Doux II (1994, flute, clarinet, and marimba), and Retrouvailles (2000, piano solo). All three pieces start with an all-interval tetrachord (AITC; set-class 4-z29), one transposition of which forms a musical cipher for "Boulez," using a mixture of French and German note names: B-(flat) [o], U(t), L(a), E [z] = bb, C, A, E (Example 3 shows the opening of Esprit Rude/Esprit Doux I). Retrouvailles and Esprit Rude/Esprit Doux I begin with statements of the AITC at the pitch level that ciphers Boulez's name. ${ }^{(21)}$ In writing these ciphers, Carter performs the basic act of encoding Boulez's name into a favorite tetrachordal set. Austin further glosses behabitives as "reactions to other people's behavior" ([1962] 1975, 160), which squares nicely with the fact that Carter was certainly acknowledging Boulez's own use of a musical birthday cipher for Paul Sacher - the SACHER hexachord (one instance of set-class 6-z11: Es, A, C, H, E, Re) - in pieces such as Répons, Dérive 1, and Incises. ${ }^{(22)}$ We can understand this allusion to Boulez's use of ciphers as one factor that enhances the ability of Carter's pieces to bring off the act of honoring or congratulating Boulez on the occasion of his birthday.

[2.2.8] Finally, illocutions of Austin's fifth category are called expositives, and these analogize to acts of reference, expression, and disclosure through music. Thus, any uses of music to refer to things, like the oft-cited parade of topical references at the opening of Mozart's F-Major Sonata, K. 332, are acts of reference and uses of musical sound to point to particular extra-musical signifieds.

(23) This fifth category hints at a major implication of Austin's thought, which is that constative tasks of referring to, and predicating about states of affairs are always already performative utterances because they are acts. 
[2.2.9] Austin found that many sentences without the explicit structural characteristics of performative formulas (such as his initial four examples of performative utterances), nonetheless implicitly perform speech-acts anyway. ${ }^{(24)}$ For instance, in saying, "I'm cold," you may implicitly be saying, "I hereby request that you shut the window," "I assert that I am aware of the temperature," "I judge the caulking to be shoddy," all of the above, and so on. ${ }^{(25)}$ Whatever particular illocution the utterance of "I'm cold" performs will be a matter of a variety of contextual features, and any particular utterance may perform multiple different illocutionary acts simultaneously.

[2.2.10] It is not simply the case that a speech-act works by virtue of being uttered; certain social conditions allow or otherwise help an utterance to perform certain acts, and thereby to result in its effects. In the literature on speech-acts and performative utterances, the situational conditions that encourage or allow for the successful accomplishment of performative speech-acts are called their felicity conditions ([1962] 1975, 12-24). Thus, one cannot sentence a prisoner to death without being a judge, nor can a judge utter "I hereby sentence you to die by hanging" without doing so as the judge in a capital punishment proceeding and without having been first delivered a corresponding verdict by the jury. ${ }^{(26)}$ Similarly, to return again to Debussy and Tristan, the fact that mm. 2-4 of Golliwog's Cakewalk enharmonically respells the first instance of the Tristan chord (F, G\#, B, Eb) might be considered a felicity condition that supports the subsequent quotation, enhancing its legibility and foreshadowing it. ${ }^{(27)}$

[2.2.11] The efficacy of speech-acts stands to be determined in terms of appropriateness and inappropriateness to context as well as effectiveness or ineffectiveness in context. ${ }^{(28)}$ As Pierre Bourdieu explains, this efficacy "does not reside ... in the discourse itself, but rather in the social [felicity] conditions of production and reproduction of . . language" (1991, 113). Bourdieu continues, "the symbolic efficacy of words is exercised only in so far as the person subjected to it recognizes the person who exercises it as authorized to do so" (116). The potentials for musical utterances to perform various illocutionary acts are not inherent properties of the music itself, nor are they under the sole authorship of a composer's intentions. They instead require an implicit "ratification" as well by the jury of the public to whom they are addressed. This "ratification" occurs via our proclivities to recognize these acts and respond appropriately, even if implicitly.

[2.2.12] As literary theorist Douglas Robinson contends, "There is no such thing as an utterance that does not perform a speech act. All language does things. All saying is also a doing" (Robinson 2005 , 45). There is no such thing, then, as categorically "performative music" or "constative music." Anytime music is interpreted as meaningful, we are catching it in the act of a doing. Likewise, there is, strictly speaking, no such thing as "performative musical analysis" or "constative musical analysis" - although the analyst certainly may adopt a primarily performative-based or constativebased attitude. Jeffrey Swinkin demonstrates this attitudinal shift: "Take a structural attribution in the form 'musical entities $x$ and $y$ are related in $z$ way'. . . I argue that one does better to view this attribution not as an objective fact but as an implicit directive [an exercitive act]: 'hear $x$ and $y$ as related in terms of $z$; imagine that relation obtains. . . I It implicitly beseeches the listener to hear something a particular way" (Swinkin 2016, 21-22). Performativity and constativity are best understood not as taxonomic designations. They instead name attitudes of taking interest in music in view of its performative action-character and efficacy, or in view of its constative capacity to disclose and depict.

\subsection{Two Further Refinements: The Act-Effect Distinction and the Status of Intentions}

[2.3.1] Illocutionary acts should be distinguished from what are called their perlocutionary effects - literally, what effect is achieved by the locution's being uttered (per-locution). Austinian theory makes the crucial insight that the acts produced by an utterance are distinct from the effects they engender. Consider the moment in the second movement of Schubert's D. 960 piano sonata that begins with the dominant pedal on $\mathrm{G} \#$ (mm. 98-102), right after the beginning of the $\mathrm{A}^{\prime}$ section in the overall ABA' form (Example 4). We could gloss the illocutionary act of this dominant pedal as committing to a certain course of action (resolution to tonic C $\$$ minor), prompting certain

expectations, or proposing to certain structural consequences. In a more metaphorical register, we 
might hear it as a warning that the bleak $\mathrm{C} \#$-minor tonic will persist, or as coaxing one's hearing into an illusory and transient major-mode key area, as in the corresponding turn to E major in the A section. Measure 103, however, does not usher in the C\#-minor tonic, but follows with an astonishing movement to $\mathrm{C}$ major. This is to say that we can recognize a musical utterance's acts of proposing a tonic resolution, prompting such expectations, and committing to particular consequences even if the utterance fails to bring those consequences about. Music's illocutionary acts stand in distinction from the consequences they bring about, what Austin called perlocutionary sequellae.

[2.3.2] Perlocutionary effects are considerably more theoretically slippery than illocutionary actsone reason why it stands to reason that the lynchpin of Austin's theory of speech-acts is not the theory of language's effects per se but the illocutionary theory of actions and their relation to various effects. Suffice it to say for now that some perlocutionary effects may be expected, intended, or conventional, while others may be less so. The turn to $\mathrm{C}$ major as above may (predictably) cause a listener to experience surprise, possibly astonishment; it might cause an analyst to think back to the corresponding spot in the A-section when a G\# dominant gave way to E major; it is conceivable (but much less likely) that it could cause one to experience fright because of a peculiar association between $C$ major and a childhood trauma, for instance. These possibilities demonstrate simply that perlocutionary effects are deeply contingent and demand to be evaluated on a case-by-case basis. ${ }^{(29)}$

[2.3.3] We can speak of the movement here from $\mathrm{V}$ to, literally, bI in terms of further illocutionary acts (Example 5). This motion, in effect, declines a tonic resolution to $C \sharp$ minor, refuses a normative option, contravenes expectations, and so forth. We might frame this moment in terms of certain affective consequences, such as experiencing surprise. But suppose that a pianist or indeed an entire audience has played or heard the movement countless times, and the motion from $\mathrm{V}$ to bI no longer generates surprise for them. This does not prevent the pianist's recognition that the moment contravenes local expectational norms and amounts to a momentarily counter-normative motion, whether or not the affective experience of surprise, catharsis, a sense of relief from the tragic mood of the movement, or any others actually come about. Any effects that an utterance may give rise to, in Austin's logic, presuppose and stand analytically distinct from the efficacious actions performed by an utterance. Actions can generate a manifold of effects. A performative-utterance concept of musical meaning identifies these and other acts not simply as the elements of an account of what the C-major episode (or the movement as a whole) represents, depicts, or narrates, but instead identifies the act-dimension of musical utterance as the ground out of which meaning attributions can arise. In a hermeneutically inclined register, Eric Wen (2016) suggests that the C-major turn represents momentary transcendence, depicts impossible hope in the face of the inevitability of the $\mathrm{C} \#$-minor tonic, and narrates farewell and transfiguration stand. But these are simply yet more illocutionary acts.

[2.3.4] For the study of music's communicativity, Austin's concept of illocutionary acts provides an important insight: musical utterances perform actions beyond the level of intramusical mapping and extramusical reference, on the one hand, and its affective, psychological, motoric, behavioral, emotional, ideational consequences, on the other hand. These two dimensions were recognized in Schubert's time as criteria for musical meaning, as in a famous letter of Mendelssohn's concerning meanings in his Songs without Words: "The thoughts which are expressed to me by music are not too indefinite to be put into words, but on the contrary, too definite... The same words never mean the same thing to different people. Only the song can say the same thing, can arouse the same feelings in one person as in another" (cited in Treitler 2011,5). This account is telling, despite its uncomfortably universalizing idea that musical sound always strikes people in the same ways, because it acknowledges both (constative) expression and (perlocutionary) arousal of feelings through musical sound. ${ }^{(30)}$ However, the concept of illocutionary acts addresses a logical lacuna in Mendelssohn's remarks: it enables us to recognize the actions performed by musical utterance, which are logically prior to the effects or consequences resulting from musical utterance. ${ }^{(31)}$ Analysis of illocutionary acts, as distinct from their perlocutionary effects, thus enables us to bridge a gap between musical denotations/connotations and their consequences, effects, and affective perlocutionary results. 
[2.3.5] Another refinement to the theoretical framework sketched above concerns the status of the meanings intended by speakers, composers, performers, writers, and analysts. The speech-act theoretic perspective would imply that the intentions of speakers and composers alike do not hold a monopoly on meanings. Yet, it seems absurd to say that intended meanings do not matter at all, dispossessed in favor of utter contextualism. The efficacy of performative utterances cannot be totally known and controlled by a willful subject, but neither can responsibility for speech-acts' effects be placed entirely on the abstract shoulders of "context." (32) The agency and efficacy of performative utterances is best understood as situated within what philosopher José Medina describes as a hybrid notion involving the "dialectical relation between contextual constraints and discursive freedom" (2006, xiii). Further questions follow from this hybrid account of utterance's efficacy: what contextual features (and which contexts in the first place) encourage us to perceive and take an interest in some illocutionary forces of an utterance over all the others, and what relevant perlocutionary sequellae follow? When are intended meanings sufficient to analyze the efficacy of utterances, and when do the meaningful efficacies of utterances exceed intended functions? ${ }^{(33)}$ For whom, and under what conditions, do music's action's result in certain meaningful consequences rather than others?

[2.3.6] Austin's novel way of studying language (by looking at the actions that language performs in ordinary situations of its usefulness) has dramatic implications, including an important figureground reversal. The uses of signs - to create, transform, maintain, or destroy various conditions in the world through their efficacy - do not simply accrue on top of what they "say" or "mean," as the old view would have it. Instead, "saying" and "meaning" are fundamentally uses to which sign are put (uses which might amount to further acts). Judy Lochhead points out that recent philosophy, including Austin's, "recognizes that words do not transparently represent the world; rather, they contribute to the fabric of the world in a dynamic and ongoing process of discourse," (Gallope et al. 2012, 235). Linguistic anthropologist Michael Silverstein words it more strongly: "Reference itself is just one, perhaps actually a minor one, among the 'performative' or 'speech-act' functions of speech. We often use basically 'descriptive' linguistic structure to accomplish other communicative goals; description happens to be one of those goals, one that overlaps in formal structure of signals with other functional ends" $(1976,14)$.

[2.3.7] In their challenge to the paradigm of meaning-as-mapping, Austin and Wittgenstein expose the ideological character of the prioritization of the constative functions of signs, thereby disrupting the smooth , tacit operation of this ideology. ${ }^{(34)}$ As philosopher Nancy Bauer argues, Austin's theoretical pursuits point "to a dimension of our sentences apart from which they not only would not do anything but also would not mean anything, except, perhaps, in seriously impoverished ways" $(2015,88)$. Speech-act theory certainly suggests some ways to follow through on Martin Stokes's (1994) injunction that we must look at what music does as much as what it represents. But more accurately, it proffers a new logic, allowing us to look at "representing" as one among many things one can do with music. This ultimately opens out into reordering what we think of as musical meaning by disrupting the surety with which we conflate representational structures with meaning as such. ${ }^{(35)}$ The arguments advanced by ordinary language philosophy propose a fundamental philosophical corrective: that a new center within the study of language and signs might be found in the ways they are used to apply pressure to the world, and how weas part of the world that signs help to make-find ways to comport ourselves to those pressures according to our goals, activities, and concerns. ${ }^{(36)}$

[2.3.8] Moi explains, “once ordinary language philosophy has finished its analysis, we no longer have any reason to construct an elaborate theory of how to avoid or get past representation. In other words: when representation loses its status as the definition of 'language' as such,' it no longer seems urgent to elaborate complex theories to find a way around it" $(2017,14)$. Ordinary language philosophy invites us to thoroughly rethink how we conceive of music-language parallels and enjoins us to rethink the grounds upon which we motivate other programs of study such as affect theory or new materialist studies by rejecting those parallels. ${ }^{(37)}$ Dealing adequately with the thought of Austin, Wittgenstein, and related thinkers requires us to hold in abeyance our previous intuitions about whether or not ideas of language, semiotics, and communication are productive models for understanding musical meaning. These thinkers repour the very foundations of the analogy that supports those models, and enjoin us to rethink both the acceptance and rejection of 
those models, since both have occurred-according to this logic-on the basis of a flawed picture of what language meaning, communication, and utterance consist in. Pace Jankélévitch ([1959] 1996) and his insistence upon an absolute difference between music and language, traversing that span may well look different from a different crossing, and when equipped with different technologies. (38)

\subsection{Beyond (But Not Against!) Constativity in Musical Scholarship}

[3.1.1] The bias towards thinking of the meaning of interpretable objects and utterances in a constative fashion is a deep-rooted aspect of Western thinking. The elucidation of this bias is one of Michael Silverstein's characteristic concerns. He explains why linguistic anthropology privileges language above the other anthropologically meaningful aspects of situations in which language is produced, pointing out that:

The ultimate justification for the segmentation of speech from other signaling media lies in one of the purposive uses that seems to distinguish speech behavior from all other communicative events, the function of pure reference, or, in terms more culturally bound than philosophical, the function of description or 'telling about'. . . It is this referential function of speech and its characteristic sign mode, the semanticoreferential sign, that has formed the basis for linguistic theory and linguistic analysis in the Western tradition. (Silverstein 1976, 14)

This suggests that tendencies to view musical meaning in similar terms - in a (relatively) referential frame concerned with getting to know what musical sound "tells" us - are likely historically and ideologically contingent consequences of the tendency to conceive of language in terms of a single chief function: referentiality. However, this by no means represents a transcultural, universal model of "the way meaning is."

[3.1.2] We can present empirical counter-evidence to the idea of meaning-as-mapping and constativity as transcultural, universal precepts about meaning. In a working paper, Silverstein recounts some of his fieldwork in Australia:

My aboriginal friends in Northwestern Australia, for example, the Worora people, had no idea what I was talking about . . . when I said, 'What does that mean?' or 'How do you say. .. ?' ... What's so interesting is that the concept of giving an equivalent to something like English language or Creole meaning was not something that ever occurred to them. Or if I asked the other way around, hearing a word and saying ... 'What does that mean?' - I would get an answer like 'I would never say that in front of my mother's brother.' (Silverstein 2014, 2)

Silverstein later concludes that his aboriginal ethnographic subjects privilege a use-theoretic concept of meaning: the way one does things with words is the most basic way for language to mean in Worora linguistic culture. He recalls: "It was their system of understanding praxis, of contextualized usage, and that was their system of meaning" (2). Silverstein in no way denies that there is a dimension of language meaning that is denotative, and semantic, and productively stands to be understood that way, but argues that the vast majority of "language-ing" (cf. Christopher Small's musick-ing) falls outside the purview of the constative, semantic view of language.

[3.1.3] According to Silverstein, the idea that linguistic meaning is fundamentally based on a denotational structure-in which the most central elements are the mappings between words, concepts, and things - is itself a sort of cultural belief system that has been so wildly successful in the West as to become seemingly universal. ${ }^{(39)}$ His fieldwork suggest that our tendencies in conceptualizing the very question of how music means are also contingent, likely conditioned by this cultural belief system that privileges the denotational capabilities of language.

\subsection{Examples of Constative Orientations}


[3.2.1] At this point, it will be informative to demonstrate the variety of forms that constative approaches to musical meaning can take. The aim of this sample of constative-oriented inquiries into musical meaning is not to describe constative approaches to meaning as any less virtuous than ones based on performative utterance, but rather to show the underlying commonalities between sometimes widely disparate logics of constativity and to argue on behalf of the greater logical generality of the performative utterance concept. Philosopher Stephen Davies summarizes constative logic and its prevalence within the discourse on musical meaning. I have underlined constructions that point to this bias:

The debate concerning musical meaning has been limited to considering what music conveys, how it does so, and what it means for it to do so. These questions ask what music refers to (or denotes, signifies, stands for), or what it represents (or depicts, describes), or what is expressed through it. Without playing down their differences, one can see that these notions all imply a conception of meaning according to which a meaning-bearer communicates a content that exists independently of itself. (Davies $2011,71)^{(40)}$

[3.2.2] Before the disciplinary turn to musical meaning and criticism of the early 1990s, the groundwork had already been laid for largely constative explorations of musical meaning in a number of earlier works. A signature example of this understanding of meaning appears in Deryck Cooke's (1959) The Language of Music. Cooke denies strict semantic claims, arguing that no dictionary of musical objects can be formulated. But he also argues that certain gestures are part of a vocabulary of the emotions, demonstrating how musical figurations from a wide historical range appear in similar expressive contexts. He applies a linguistic ideology that locates meaning in transhistorical, stable "essences" of meaningful units. Wilson Coker's Music and Meaning (1972), known for its bipartite theory of congeneric and extrageneric musical reference, similarly relies on locating meaning in a stable nucleus of sorts, bracketing out context and privileging the semantic: "The sentient attitudes that music expresses are there objectively in tone and rhythm as such" $(1972,148)$. Jerrold Levinson (1981) speculatively articulates a set of criteria for assessing truth or falsity conditions in music: musical object $X$ expresses thing $Y$, genuine musical expressions are those that are intended, music expresses that $X$ and $Y$ go together, music expresses that $X$ is followed by $Y$. All of these early efforts locate the connection between musical and linguistic meaning around forms of mapping. A formidable sub-discipline of music semiotics has subsequently matured. ${ }^{(41)}$

[3.2.3] A very different manifestation of meaning-as-mapping informs cognitive theory having to do with body-derived image schemas. The cornerstone examples of this theoretical work aim to provide cognitive-psychological accounts of the constative functions of music qua utterance, proposing a mechanism by which musical objects pick out their narrative, imagistic, or verbal correlates. For example, in Candace Brower's (2000) essay, "A Cognitive Theory of Musical Meaning," basic schemas such as MUSICAL EVENTS ARE ACTIONS and A MUSICAL WORK IS A JOURNEY prop up connections between particular musical objects and particular embodied experiences, or between particular musical works and particular journey plot-structures. She discusses Schubert's "Du bist die Ruh"” and demonstrates how the music, via the image schemas associated with it, discloses meanings that poet Friedrich Rückert's text does not. For instance, she applies the CONTAINER schema to analyze the final two phrases of the song, which feature dramatic melodic ascents that tonicize the subdominant (Example 6). I have underlined constructions buttressed by constative meaning claims:

In the poem, the eyes and heart are represented as metaphorical containers, filled, respectively, with the radiance of the beloved and feelings of joy. What the words do not specifically describe, yet the music conveys, is the expansion of these two metaphorical containers. It is not until we hear the final words of the text, $\mathrm{O}$ füll' es ganz! (O fill it full!) that we fully grasp the meaning of the climactic phrase. Its remarkable expansion conveys the image of these two bodily containers being filled to their fullest extent, an image that becomes increasingly vivid as we approach the end of the phrase (Brower 2000, 369). 
Here, the music discloses and depicts various meanings in conjunction with its text via the mediation of a schema involving a CONTAINER being filled to its brim, also invoking ASCENT or VERTICALITY schemas that draw on embodied experiences of rising and falling motions caused by the Earth's gravity. In this analysis, the song tells about an implied energetics of filling the eyes and heart full and discloses its schematic bases as well. Cognitive image schema theory may offer a psychological mechanism derived from embodied, actional experience by which to account for musical meanings, but the theory operates in service of accounting for semantic mappings between musical objects and particular referents.

[3.2.4] Other constative logics apply to musical meaning in the hands of a variety of authors associated with the "New Musicology" and the turn in the late 1980's and early 1990's towards producing scholarship about musical meanings. Susan McClary (1994) writes that Schubert's Unfinished Symphony reveals things about gender constructions in the early 1800's, that in it, Schubert expresses personal difference and discloses a model of male sexuality that would later undergo certain marginalizations. Music is figured here according to what linguists would call a "conduit metaphor" (Reddy 1979), where music is involved in the delivery of packets of decodable information. "Although we often speak of Schubert as if he managed to transmit his own subjective feelings directly into his music," McClary writes, "these 'feelings' had to be constructed painstakingly from the stuff of standard tonality" $(1994,222)$. It is not that McClary or others are uninterested in music's effects, its consequences, and the actions that it performs. Quite the contrary: McClary's essay is about how music works in fashioning subjectivities. However, the overall frame of thought seems to be one in which it is necessary first to invoke a theory of how music as utterance represents the world, after which we can move on to thinking about how that musical utterance affects, shapes, and creates action in the world. It is this ordering that I want to call into question. The disclosures of music (and language) are always already preceded by their usability to disclose and their situatedness within lived scenarios that motivate those disclosures. ${ }^{(42)}$

[3.2.5] Constativity does not need to involve extramusical referentiality at all. Constativity proceeds through the logic of the meaning-as-mapping framework and thus may pertain as well to intramusical meaning. Leonard Meyer's (1956) account of intramusical meaning depends on a mapping produced by psychological and enculturated processes of expectation. Meyer calls this form of intramusical meaning "embodied meaning," yet he recruits an essentially referentialist logic in identifying as the crux of intramusical meaning the mapping between particular musical stimuli and their structural consequences or sequellae.

\subsection{Towards Performative, Act-Centered Approaches}

[3.3.1] However, Meyer's views can be difficult to characterize since he was aiming to theorize nothing less than musical experience. Meyer's psychological and behaviorist framework characterizes an acoustical datum in music and the expectations it generates by relating them as stimulus (i.e., musical object) and response (expectational structures). While the act-dimension of musical meaning is not fully demarcated and specified in Meyer's account, his discussion of musical meaning suggests it. Meyer heavily qualifies his attribution of musical meaning to expectational mappings: "It is pointless to ask what the intrinsic meaning of a single tone or series of tones is. ... They become meaningful only insofar as they point to, indicate, or imply something beyond themselves. .. . Meaning, then, is not in either the stimulus, or what it points to, or the observer" $(1956,34)$. That is, a musical entity's meaning is not an inherent property of the music itself, nor is it reducible to the effects or consequences it generates, nor is it entirely a matter of the subjective proclivities of any unique listener.

[3.3.2] Meyer is articulating something in defining the negative space around it. He eventually concludes that meaning lies in the "triadic relationship" between the musical object, that to which the musical object points (its "consequent"), and an enculturated listening subject. ${ }^{(43)}$ It stands to reason that we could go one step further and understand the foundation that subtends these three nodes as the illocutionary acts of intramusically meaningful tonal structures. These relations are schematized in Example 7. Musically meaningful structures, in Meyer's account, prompt enculturated expectations; they suggest or imply particular stylistically sanctioned consequents. By 
this logic, an act of generating expectations is implicated in musical meaningfulness, alongside the musical objects and expectations themselves. This is a subtle but necessary proviso. A listener's recognition of an expectational structure would be an example of what Austin called uptake: the recognition and attribution of a particular illocutionary act as pertaining to an utterance. Logically prior to this uptake, then, would be that which is taken up: the illocutionary act of suggesting, implying, or prompting an expected structure, an act which, like Austin's speech-acts, depends on certain felicity conditions being met-here, minimally, the enculturation of the listener into systems of tonal syntax.

[3.3.3] David Lewin's (1987) transformational theory, particularly the much-discussed "transformational attitude," also prioritizes a notion of acts. Lewin's overall vision of a methodological shift towards attending to the act-dimension of his topic mirrors fortuitously Austin's vision of a methodological shift towards the act-dimension of his. The raison-d'etre of transformational theory was to challenge the objectification of musical entities even as basic as a dominant chord, locating the idea of the dominant in its act-character, which stands anterior to its object-character. For Lewin, the dominant is not merely a label for a collection of notes in a syntactically determinate position. It is more than a label for a set of tendencies, and ultimately even more than way of referencing what he calls "kinetic intuitions" (bringing Meyer's embodied meaning to mind), though he does not deny any of these positions outright. Instead, Lewin specifies the dominant as a transformational operation that drives transformational graphnetworks, as an act that directs tonal gravity towards the tonic. Though Lewin's account does not explicitly address itself to issues of musical meaning, we can attend to a nascent illocutionary force potential ascribed to the dominant as a tonal transformation. It proposes a tonic resolution; it anticipates scale-degrees 1, 3, and 5; it primes a directed motion to the contextual I harmony, it drives the transformational network. These illocutions of the dominant may then be followed by various perlocutionary sequellae: actually achieving the tonic and confirming tonal expectations, forestalling the tonic and prolonging an expectational structure, splitting the difference with a deceptive resolution, and so forth. ${ }^{(44)}$

[3.3.4] Music analysis is no stranger to the notion of act-potential when dealing with musical objects and their functionality in context, yet there is a mismatch between this implicit recognition of performative act-potential and the broad tendency to make explicit attributions of constative meaning-as-mapping to musical objects when "meaning" comes to be at issue. Accounts of musical meaning that privilege forms of symbolism and referentiality ultimately fail to underwrite musical efficacy and can only gloss any relevant effects that take place as a lacquer on top of that which is disclosed in musical utterance.

[3.3.5] Contrasting the performative, speech-act theoretic attitude with the constative attitude, we might (semi)-formally characterize musical meaning statements like so:

(Constative): the meaning of $\{$ MUSICAL OBJECT $\}$ is: mapping to $\{\alpha, \beta, \gamma \ldots\}$

(Performative): the meaning of $\{$ MUSICAL OBJECT $\}$ is: that it does $\{X, Y, Z, \ldots\}$

The performative, use-theoretic idea of meaning sketched above suggests a grounding for a more general and encompassing account of musical meaning: the constative frame's "mapping to $\{\alpha, \beta, \gamma$ ... $\}^{\prime \prime}$ is a proper subset of the performative frame's $\{X, Y, Z, \ldots\}$, a set encompassing the different forms of "doing things" with and in the face of music's communicativity and meaningfulness. As Wittgenstein argues, it is impossible to disaggregate "the meaning itself" from "doing things" with signs: "How is what [signs] signify supposed to come out other than in the kind of use they have?" ([1953] 1958, §10). Moi, elaborating upon Wittgenstein's position, writes: “It would be easy to conclude that we are to attend to what we do with words rather than what they mean. But if that were our conclusion, we wouldn't be getting the point after all, for here the word 'rather' gives us the wrong idea" (2017, 28-29). Instead, the perspective elaborated here eliminates the binary opposition between what music "says" and what it "does," categorizing both as forms of action.

\subsection{Theorizing "Performativity" as a Critical Term}


[4.1.1] Literary theorists Andrew Parker and Eve Kosofsky Sedgwick say it best: the questions raised by “J. L. Austin's How to Do Things With Words ... have resonated through the theoretical writings of the past three decades in a carnivalesque echolalia" (Parker and Sedgwick 1995, 1). The decades since the publication of Austin's treatise have witnessed an unusually wide dissemination of concepts of performativity at large, and a dissemination of the specifically Austinian valences of speech-act theory into not only linguistics and analytic philosophy of language, but also into continental theory and poststructuralist thought via Jacques Derrida ([1972] 1988) and Judith Butler (1997), as well as into anthropology, theater, film, photography, performance studies, theology, and even economic theory. Parker and Sedgwick note that, "given these divergent developments, it makes abundant sense that performativity's recent history has been marked by cross-purposes. For while philosophy and theater now share 'performative' as a common lexical item, the term has hardly come to mean the same thing for each" $(1995,2)$.

[4.1.2] Fields of musical scholarship in recent decades have made ample use of Austin's terminology without necessarily activating the specifically Austinian valences and commitments they carry. This is one of the special problems the case of music poses for a speech-act theoretical account of its meanings: how to productively understand interacting but conceptually distinct usages of the term "performative." Ethnomusicologist Alejandro Madrid sums up the situation in relation to the work of scholars in performance studies:

When most musicians talk about 'performativity' they have in mind something quite different from what scholars in performance studies do. ... The type of performance questions entertained by [traditional music scholarship] remain within the realm of the rendition of a musical text, the 'how' to make such texts accessible to listeners, musical performances as texts, or at best, how the notions of performance and composition might collapse in improvisation. In such a context, the term "performativity" refers to the means by which music is created or re-created in performance. (Madrid 2009, [2])

With Madrid, I argue that when we speak of "performativity", we are speaking, in principle, of two construals of the term, combined in some ratio. One usage, not necessarily operating in view of Austin's work, links "performativity" to performances, metaphors of the stage, and theatricality. Another usage, which does operate in view of Austin's work, links "performativity" to the much more everyday idea of performing actions and deeds.

[4.1.3] ( $\mathbf{P}_{\mathbf{1}}$-PERFORMATIVITY): $\mathrm{P}_{1}$-Performativity refers to performers and their bodies, the liveness of performances, the fact of presence, and the materiality or eventhood of performing. It refers to how performance takes place on stages before audiences, requiring the expenditure of human conduct to happen, and calling attention to the presence of those who perform actions. Under this rubric, we might talk about specific performances and stagings of musical works, the theatricality and artifice involved in doing the performance, or how works and situations of musicmaking reveal the (perhaps virtuosic) efforts and enactments of presence required to produce them. Centrally at issue for the thinking that implements $\mathrm{P}_{1}$-Performative logic is a dichotomy between materiality, presence, and the body, on the one hand; and categories of the ideational, conceptual, and the mind, on the other hand.

[4.1.4] ( $\mathbf{P}_{2}$-PERFORMATIVITY): $\mathrm{P}_{2}$-Performativity instead highlights semiotic efficacy. If $\mathrm{P}_{1^{-}}$ Performativity asks what sorts of actions, presences, and conduct lie behind and result in acts of music making, events of speaking, theatrical performances, works of visual art, and so on, then $\mathrm{P}_{2^{-}}$

Performativity asks how action and conduct emanate outward from things like pieces of music, painting, sculpture, or staged performances. If linguistic speech-act theory asks how saying something counts as doing something under the rubric of $\mathrm{P}_{2}$-Performativity, then in the general case this rubric seeks to account for how semiotic entities (linguistic or non-linguistic) possess abilities to produce realities and regulate their scenes of address, contexts of witness, situations of hearing, and so forth. $\mathrm{P}_{2}$-Performativity is externally directed: it refers to how a sign or discourse segment manages some aspect of the reality it takes place in, whether fictional or actual. Centrally at issue for the thinking that implements $\mathrm{P}_{2}$-Performative logic is the constative/performative

distinction from Austin's work. 
[4.1.5] As Example 8 illustrates below, $\mathrm{P}_{1}$-Performativity

and $\mathrm{P}_{2}$-Performativity designate distinctly different mechanisms for speaking of "performativity" in relation to the musical, verbal, or artistic object of consideration. Example 8 notes a certain conflation that can occur when speaking pre- theoretically about what aspects of music, language, and other forms of utterance are "performative." This theorization of the term "performativity" ultimately has in mind the goal of better enabling scholars of performing arts and scholars of language to engage in dialogues around a contested term.

[4.1.6] $\mathrm{P}_{1}$-Performativity emphasizes the fundamentally performed nature of music, its liveness and its theatricality. Stephen Rumph, for example, describes Fauré's allusions to theatrical song styles in his own songwriting as performative, thereby drawing on the "performative" to activate theatrical resonances of stage presence and artifice: “Like many French composers, Fauré drew upon theatrical song in his mélodies, introducing a performative element that encourages distance as well as absorption" $(2015,558)$. Nicholas Cook describes "the analysis of musical performance as a model for the performativity of analytical writing in general" $(1999,251)$, suggesting that reading analytical writing can be like witnessing a virtuoso artist commanding a stage. $\mathrm{P}_{1}$-Performativity, in the hands of these authors, is a way of invoking metaphors of stage and theater.

[4.1.7] $\mathrm{P}_{1}$-Performativity is frequently mobilized by the discipline's recent tide of attention to the carnal, material aspects of music and music making. Roman Ivanovitch deploys the term "performative" in connection with the physical body and liveness of the virtuoso performer: "Showcasing sheer performative prowess, and built from the common fund of stock figuration, sequential patterns, and cadential clichés, it is easy to see how these spots underscore the fragile nature of the pact the concerto makes between 'virtuosity' and 'substance'" (2008, 183). Anna Gawboy introduces the term "performativity" in her remarks on Charles Wheatstone's concertina to refer to the (imperfect) adaptation of the instrument to the bodies that would wield it:

"Wheatstone's button designs, then, can be appreciated from a purely practical standpoint. However, the slight awkwardness presented by each layout suggests that performativity was not the sole consideration" $(2009,174)$.

[4.1.8] The logic of $\mathrm{P}_{1}$-Performativity states that human action and performer conduct are inputs from which the event of music making results. It foregrounds a shift from attending to musical works-as-texts to focusing on the efforts that performers expend to realize musical works. This rubric thereby allows us to challenge the hegemony of a work-centric and composer-centric orientation to the study of music. In contradistinction to theories of linguistic performativity and Austinian speech-act theory, however, $\mathrm{P}_{1}$-Performativity maintains close ties with a logic of constativity and disclosure. When describing musical works or events as $\mathrm{P}_{1}$-Performative as above, we are essentially describing how the works disclose the bodies or actions of performers, or how they make reference to the theater and stage. It should be noted that Austin would have roundly dismissed any thinking in terms of the ways in which "performative" utterance resembles theater and stage shows, having once described the speech-acts made in a theatrical work or fictional setting as "etiolated," "hollow," and "void" ([1962] 1975, 22).

[4.1.9] A musical $\mathrm{P}_{2}$-Performativity does not attempt to overwrite the claims of $\mathrm{P}_{1}$-Performativity but accounts for entirely different processes. $\mathrm{P}_{1}$-Performativity describes what bodily, actional inputs result in the utterance/text/work as an output, while $\mathrm{P}_{2}$-Performativity accounts for the utterance/text/work as an input to then document what further situations are created as a result. $\mathrm{P}_{2}$-Performativity documents how sign systems accomplish various communicative aims beyond semantic tasks of representing reality or disclosing information: realizing social and material practices, managing experiential and epistemic realities, constructing identities and interpellating subjects, enacting power, and even inflicting injury. However, this is an analytic distinction, not an empirical one: neither $\mathrm{P}_{1}$-Performativity or $\mathrm{P}_{2}$-Performativity occur without the other. Thus, in any given situation, we may be interested in either $\mathrm{P}_{1}$-Performativity or $\mathrm{P}_{2}$-Performativity and their logics, but it would be a category mistake to claim that any music is $\mathrm{P}_{1}$-Performative or $\mathrm{P}_{2^{-}}$ 
Performative to the exclusion of the other. Both concepts of performativity are necessarily active in any situation of music making or music use.

[4.1.10] Another way to describe the intellectual project associated with $\mathrm{P}_{2}$-Performativity would be to say that it frames semiosis and discourse as ritual and ceremony, a recognition that developed in social scientific research prior to its interactions with ordinary language philosophy and Austininspired linguistics. ${ }^{(45)}$ Such understandings of "performativity" have influenced anthropologically-inclined performance studies research (Turner 1982; Schechner 1985; Phelan 1993; Jackson 2004.) Any speech-act or performative utterance, be it verbal language, music, or otherwise, is imbued with the power to produce and manage realities by virtue of being spoken, produced, or uttered under the correct contextual conditions. Pierre Bourdieu calls this the "social magic" of performativity: "magical" in the sense that the efficacy of performative semiosis is secured not through expending physical or mechanical efforts, but rather through an incantation of sorts (Bourdieu 1991; Butler 1999). We might describe the $\mathrm{P}_{2}$-Performative efficacy of a musical utterance with the metaphor philosopher Mats Furberg uses to describe linguistic performatives: “Their speaker as it were presses a button in a social machine" $(1967,453)$.

[4.1.11] A third theoretical vantage point that hybridizes $\mathrm{P}_{1}$-Performativity and $\mathrm{P}_{2}$-Performativity should be clarified. Posthumanist thinkers Donna Haraway (1988) and Karen Barad (2003) describe what they call the "material-semiotic" nature of discursive practices, stipulating that the production of discourses and signs involves material bodies (including, but not limited to, human bodies). Discourses may then go on to act upon and entail consequences for lived and, hence, material practices. This conception of performativity lies at the heart of, for instance, the bodily, material-discursive performativity of identities. Judith Butler's (2002) work on the bodily performativity of gender, identity, and collective publics highlights the ways in which bodily acts "stage" eminently material performances of identity ( $\mathrm{P}_{1}$-Performativity) and highlights how these acts go on to have entailing effects in that they affirm, manage, and constitute the formation of the subject ( $\mathrm{P}_{2}$-Performativity). In her afterword to Shoshana Felman's The Scandal of the Speaking Body, Butler writes that discursive-bodily acts "draw on the body to articulate their claims, to institute the realities of which they speak" (113).

[4.1.12] This hybrid material-semiotic situation needs to be considered whenever performativity becomes an interpretive issue, since all performative functioning of signs necessarily implies the involvement of the body and material at some level (though possibly trivially), and always involves the possibility of applying pressures to the context at hand (though possibly trivially). $\mathrm{P}_{1^{-}}$ Performativity puts the embodiment and the material into the efficacy of material-semiotic acts, while $\mathrm{P}_{2}$-Performativity accounts for their semiotics and their efficacy. Within musical scholarship,

Michelle Duncan's (2004) work on the performativity of the operatic voice recruits both notions of performativity to examine what she refers to as the "operatic scandal of the singing body." Duncan argues that opera as utterance involves and calls attention to the singing body and the material performance network ( $\mathrm{P}_{1}$-Performativity), but that it also exerts effects upon its contexts of listening through the arresting qualities of the voice $\left(\mathrm{P}_{2}\right.$-Performativity). We can describe a material-semiotic matrix of oppositions into which concepts of performativity intervene, a matrix consisting of the mind/body dichotomy that $\mathrm{P}_{1}$-Performativity responds to, and the constative/performative distinction that $\mathrm{P}_{2}$-Performativity responds to. Example 9 below charts how $\mathrm{P}_{1}$-Performativity and $\mathrm{P}_{2}$-Performativity interact with the mind/body dichotomy and the constative/performative distinction. The distinction between $\mathrm{P}_{1}$-Performativity and $\mathrm{P}_{2}$ -

Performativity make clear a terminological fault line that is always straddled by invocations of the performative in musical scholarship, whether or not this straddling is recognized. This distinction serves to hone the particular philosophical understanding of performativity that this article pursues as its key intervention into rethinking musical meaning $\left(\mathrm{P}_{2}\right.$-Performativity) without embarking on the futile task of overwriting some scholars' ( $\mathrm{P}_{1}$-Performativity) usages of the term.

\subsection{Performative and Constative Features Interacting in a Piece by Alvin Lucier}


[4.2.1] Let us examine the interaction of performative and constative features of a 20th-century work that invites the multiple inflections of "performativity" as described above. The text score of American experimentalist composer Alvin Lucier's The Only Talking Machine of Its Kind in the World (1969) is printed below:

Ask friends to design a tape-delay system in the form of a totem pole, mandala, labyrinth, tree or any other visual configuration. Talk to an audience through a public address system for a long enough time to reveal the peculiarities of your speech. After the peculiarities of your speech have been revealed, your friends may begin building the tape-delay system into which your speech, tapped from the public address system, is fed. Talk, during the building of the tape-delay system, about that which will best reveal the peculiarities of your speech; but from time to time read from a text or tell a story of a people, real or imagined, who have not had or do not now have any idea about anxious speech. Continue talking after the completion of the tape-delay system until, due to the annihilation of the peculiarities of your speech by the tape-delay system, anxiety about your speech is relieved or it becomes clear that the tape-delay system is failing and will continue to fail to bring this about (Lucier 1995, 317).

[4.2.2] Talking Machine is deliberately performative in the $\mathrm{P}_{\neg 1\urcorner}$ sense: it conspicuously calls attention to the body and presence of the performer, particularly "peculiarities" of the voice. Furthermore, one can readily imagine that performances of Talking Machine are rather theatrical, and hence performative again in the $\mathrm{P}_{1}$ sense. A 2009 performance at Berlin's Festival SOLOLALA features

Swiss actress and filmmaker Adeline Rosenstein as the soloist (https://www.youtube.com/watch? $\mathrm{v}=\mathrm{q} 2 \mathrm{PxgkiLeUU}$ ). Rosenstein delivers her chosen texts from atop a crate labelled "nature's mistakes," a deliberately chosen stage prop. Her heavily French-accented English resounds through the space via the delay apparatus and amplification system. As described above, this $\mathrm{P}_{1^{-}}$

Performativity bears a constative logic: notice how Lucier's score speaks again and again of revealing the peculiarities of speech (and hence the condition of the performer's bodily habitus) within a material, staged event.

[4.2.3] There are all manner of constative, explicitly referential treatments we could make of this material. For one, it points to Lucier himself, who famously speaks with a pronounced stutter. From our historical vantage point, Talking Machine points to one of Lucier's most famous pieces, I am Sitting in A Room, in which he again recruits a tape delay system to play a recording of his speech, but this time to erase the sonic traces of his own stutter. Talking Machine also refers to a generic idea of rituals through its references to totems and mandalas, both ritual and ceremonial objects associated with forms of spiritual significance within and beyond their native cultures. In its emphasis on the sonic qualities of the speaking voice rather than the semantics of text, it points to other pieces that thematize speech as musical material, such as Steve Reich's Come Out (1966) and Different Trains (1988).

[4.2.4] However, Talking Machine also thematizes an aesthetic of efficacy in which the performance amounts to a healing procedure of sorts, relieving the anxiety of a performer regarding sonic features of their diction (or failing to bring this about). Lucier's materialist concerns with the physical acoustics of delay systems and their psychological consequences in the production of speech, do not obviate semiotic aspects of Talking Machine's efficacy. This is more than a material or affective phenomenon alone and is a phenomenon of $\mathrm{P}_{2}$-Performativity as well. Talking Machine performs illocutionary acts of proposing or inaugurating a musical imaginary in which music is taken to have certain enchanting powers to perform potentially healing work upon the performer, as might be imagined to take place in practices involving the mandalas and totems mentioned in the score. In an imaginative register, we might think of the title and the score of Talking Machine as the recipe for an incantation, so to speak, an illocutionary act of musical magic akin to enchantments, hexes, curses, charms, or spells. This analogy between Talking Machine and the speech-act characteristics of magical utterances productively captures the sense of whimsy that so often abides in Lucier's pieces in excess of their physical and psychoacoustic specifications. 
[4.2.5] The performer becomes a sort of shamanic figure on her own behalf, wherein the act of performance is used, like Austin's performative statements, to bring off certain actions and consequences: among them the illocutionary acts of masking the peculiarities of one's speech refusing one's anxieties about the sound of one's voice and the perlocutionary consequence of actually being relieved of these anxieties. ${ }^{(46)}$ Rosenstein's performance ends with a defiant "so what?" as though to declare that any discomfort about her accented English has been eliminated. Her "so what?" predicates a perlocutionary consequence of the musical performance as utterance. Rosenstein's material-semiotic acts of using her voice with the delay system appear to have been efficacious, or they are at least staged as such. Talking Machine intermingles both semiotic and bodily/material efficacies under $\mathrm{P}_{2}$-Performative logics in addition to recruiting referential, constative, and $\mathrm{P}_{1}$-Performative logics.

\section{Maxims for an Action-Based Theory of Musical Meaning}

[5.1.1] To further specify the use-theoretic notion of "meaning" I am advancing, we will now examine an argument that theorizes illocutionary acts as the very underpinnings of language meaning. I have demonstrated that constative ideologies of meaning instantiate themselves in a manifold of ways in studies of musical meaning, and I have given empirical support to the claim that the constative semantic bias is culturally and historically contingent. Now we can consider a few axioms about a $\mathrm{P}_{2}$-Performative account of musical meaning and semiosis, adapted from

William Alston's (2000) monograph, Illocutionary Acts and Sentence Meaning, a landmark text in the development of speech-act theory.

[5.1.2] First, Alston proposes use as the key to meaning, following Wittgenstein and Austin. For Alston's theory, "the fact that an expression has a certain meaning is what enables it to play a distinctive role (be used in a certain way) in communication" (154). Alston then defends the idea that this usability in situations of communication is the essence of meaning: "An expression's having a certain meaning consists in its being usable to play a certain role (to do certain things) in communication" (154). The parallel musical claims would be: some token instance of music having meaning in some way is what enables it to perform a specific role in some manner of a communication. Conversely, when a musical object has a certain meaning attributed to it, this meaning consists in its being usable to do particular things in some communicative fashion. Instances in which there is seemingly no interpersonal component (such as soloists improvising just for themselves) are still in dialogue with music's communicativity if there is any form of meaningfulness attributed to said musicking and if roles of listener, producer, and musical object/utterance, minimally, can be specified.

[5.1.3] Alston then brings Austin into the picture, refining the above to argue that the usability of a sentence's meaning in communication is due to its potential illocutionary acts: "Sentence meaning is illocutionary act potential" (160). More specifically, "what it is for a sentence to have a certain meaning is for it to be usable to perform illocutionary acts of the matching type" (160). Correspondingly, what it is for us to attend to meaning in music is for us to recognize, at least implicitly, its illocutionary act potential. Accordingly, it should be possible to rearticulate any claim towards the meaning of any musical object in terms of a corresponding illocutionary force. Whenever a claim about the meaning of some musical object is articulated, the one who makes the claim takes the musical object to have a particular illocutionary force, whether that be disclosing the socio-politics of gender circa 1800 (as in McClary's remarks on Schubert), depicting bird song (as in the incipit to Ravel's Oiseaux tristes), representing a fictional character's sexual frustration (as in Carolyn Abbate's [2004, 510] discussion of an arpeggio occurring in Idamante's "Non temer, amato bene" aria in Mozart's Idomeneo), proposing a local tonic (as in the misleading I7-IV motion that opens Beethoven's Symphony no. 1), or any others. These reformulations of meaning-attributions may be trivial when demonstrating the illocutionary forces that pertain to constative claims about musical meaning. All semantic claims can be reframed as performative utterance. However, other attributions of musical meaning cannot be cogently analyzed in semantic terms and must be articulated as performative, use-theoretic meaning-claims alone. 
[5.1.4] Given the regularity with which scholars proclaim music's semantic indeterminacy as a categorical difference between language and music, it is ironic that such considerable effort has been spent to secure music's language-character and meaning on the grounds of its capacities at least to approximate the semantic properties of linguistic meanings (as in the programs of pieces of absolute music, or in the identification of 18th-century topics in instrumental works). ${ }^{(47)}$ From the beginning, the argument presented here has worked in the other direction, by embracing the useof-musical-objects to provide the theoretical basis for music's meaning. Use and efficacy are not merely affordances of musical semantics; use and efficacy stand beneath musical semantics as the ground out of which semantic claims can even emerge at all. Hence, I argue for a pragmatics-first conception of musical meaning-as-use that ultimately underwrites both music's semantic functions and its communicative efficacies on the grounds of a performative theory of music's communicative action.

\subsection{Analytic Challenges and Speech-Act Theoretic Interventions}

[6.1.1] The theoretical corrective elaborated in this essay and the conceptual tools it brings along may be useful in gaining analytical purchase on recent music, which can be deeply recalcitrant to forms of score-based analysis and to interpretive strategies based in reference and disclosure. The theory elaborated above should be able to parsesemiotic meanings and communicative features for which constative logics are, in principle, fundamentally unsuited. It should be suitable, in principle, to analyze fault lines produced by the constative/performative distinction and should appropriate insights into the way pieces take advantage of (or stumble along) these fault lines. Furthermore, it should speak at least partly to effects of music that might otherwise stand to demonstrate its ineffability - its resistance to discursivity, semiosis, the music-language analogy - and assimilate these to conceptual apparatuses of the theory presented above. I demonstrate below, discussing pieces by Michael Beil and Peter Ablinger.

\subsection{The Performativity of Quotation: Michael Beil's Die Zwei}

[6.2.1] Michael Beil's Die Zwei (2004) consists in its entirety of a transcription for flute, piano, and electronics of the Lento assai from Beethoven's String Quartet no. 16, op. 135 (YouTube). As such, it poses an analytic riddle: how would one analyze this piece as Michael Beil's piece, and not as Beethoven's? On the one hand, we could appeal to its material differences from Beethoven's work. Beil transcribes the work for a new instrumentation, adds a video component, adds electronic sound, and adds digitally manipulated recordings of the Beethoven movement by notable string quartets. The appeal to material differences, however, has problems: it is not clear that these material differences are fundamentally different in kind from the material differences between any two performances of the Beethoven quartet, or between the original and any given arrangement or transcription of it. Instead, a theory of performative utterance provides an analytic that allows us to speak of the particular communicative actions the piece performs as those features that ontologically distinguish Die Zwei from its Beethovenian predecessor as a separate work.

[6.2.2] As Beil describes, "the Beethoven is still there, but its meaning has been lost. The source material is not altered but is nevertheless destroyed" (2011, [16]). In a metaphorical register, Beil describes a guiding image: the idea of "listening through frosted glass" (2012, 13, emphasis in the original). He writes, "the familiar is gone. This can have an uncanny quality to it-something that touches you in a totally different way from the original, maybe even in an uncomfortable way. I wasn't interested in making an arrangement, but rather an estrangement from the estrangement that Beethoven's music already embodies" (2011, [16]). This does not amount to an objectified, objectifiable "content" - located in the structures and process transmitted in the score per se-but rather an actional one. He urges, "it is of utmost importance to keep in mind that the quotation is not the material [of the work] itself, but it is rather the act of quoting that is the material for the composition. I am not interested in the original meaning that the quotation is loaded with, nor its possible new meanings in a new context" (2011, [7]).

[6.2.3] Beil thus reveals a conceptual fault line between the content transmitted by the quoting, and the act of quotation itself. This mirrors Austin's distinction between the constative contents, 
structures, and messages in an utterance, and the performative dimension of utterance being used "to do things." Beil clarifies: "I would suggest something like emphasizing [the act of] quotation itself in the conception, rather than the specific quotation" (2012,9-10). The act of quoting the Beethoven quartet movement is an illocutionary act that Beil attributes to his own piece as a compositional utterance, while ordinarily we would never attribute this act to any instances of Beethoven's original (i.e., we would not ordinarily describe op. 135/iii as a quotation of itself). Herein lies the basis for Die Zwei's work-ontological claim.

[6.2.4] Beil explains his choice of a movement from Beethoven's final quartet: "Charged, exhausted, idiomatic and unambiguous material is suitable for this purpose, as it most easily loses its meaning in the music. If one works in the right way, it is quickly recognized and quickly forgotten. As soon as it is forgotten, it becomes the carrier of the strategy with which I compose" $(2012,10)$. As such, this work mounts a fundamental challenge to locating musical meaning in the semantic contents transmitted by the score or by any token performance, shifting its focus squarely onto the act dimension: not what is "said" by the music, but what is done by its being uttered.

[6.2.5] I argue that Die Zwei is most productively read as a thought experiment that deals with the ontology of works. ${ }^{(48)}$ Its strongest ontological claim as a distinct work resides not in the contents and structures that it bears, nor in the material specificity of the electronic and instrumentational changes it makes to Beethoven's original, but in the fact that the Beil's composition, as an utterance, performs the illocutionary act of quoting Beethoven in full. He compares his strategy in this work to the use of pre-existing images in the pop-art of Andy Warhol and Roy Lichtenstein, among others, who famously repainted commercial images. These artworks perform acts including: questioning the necessity for originality of content in artworks and resituating commercial images so as to produce new pressures and new effects upon their audiences. Similarly, while it may be intuitive to dismiss Die Zwei as a thinly-veiled plagiarism or mere copy of Beethoven's original work, Die Zwei can be productively read as performing the illocutionary act of critiquing romantic work concepts fixated upon originality. These work concepts locate the identity of works in the contents and structures they bear, rather than in the actions they perform.

[6.2.6] Die Zwei's act of musical copying has other parallels in sampling practices, remixes, and mash-ups. Beil writes: "The process of copying in all its various forms has become an essential part of production in a wide range of fields. The act of copying should be thematized and used as material for musical compositions" (2011, [14]). Scholars such as Kyle Adams (2015), Ragnhild Brøvig-Hanssen and Paul Harkins (2012), Christine Boone (2013), and David J. Gunkel (2008, 2012) have explored the aesthetic, legal, and conceptual questions concerning these practices in popular music. ${ }^{(49)}$ As Gunkel notes, critical attention to such practices predictably coalesces around two positions: one that celebrates these practices for creatively modifying or recombining their source materials, and one that reviles them for their derivative, inauthentic, and even illegal uses of the intellectual property of others. Both positions, as Gunkel shows, presume that originality and authenticity are the final determinants of aesthetic and artistic merit. ${ }^{(50)}$

[6.2.7] This use-theoretic, action-theoretic articulation of Die Zwei's meaning diverges considerably from the explicit theory of meaning that Beil invokes when discussing musical meaning as such:

When I work with borrowed (familiar) material, I find it useful to differentiate between musical and extramusical connotations. Musical meanings have their origins in familiar music or reference well known musical effects, . . . sound constellations with predicable emotional effects (sadness, horror etc.), or structures that are associated with a typical musical context (a six-three chord at the beginning of a recitativo). Extramusical meanings are musical elements that listeners automatically connect with a non-musical phenomenon. . . I mean for instance things such as jingles, signals, alarms, but also the French overture or the soldier's march (Beil 2011, [9]).

He appeals to the familiar characterization of musical meaning in terms of intramusical and extramusical mappings. This account of musical meaning, however, provides little basis to account for the feature of Die Zwei that Beil evidently finds most meaningful: the distinction between the illocutionary act of quoting, and the specific contents/features of that which is quoted. 
[6.2.8] The Austinian analysis of Die Zwei can also shed light on the reception that Beil describes receiving: "While less informed listeners immediately understood the music's aim, specialists reacted to Die Zwei with disconcertment, even hostility. The cause was not usually my concept however, but rather the charge of iconoclasm, or simply repulsion towards the kitsch they assumed to be sincere." (Beil 2012, 16) This critical assessment hinges upon critics understanding Die Zwei primarily as a vehicle for the material being quoted, rather than as, primarily, an instantiation of the act of quotation. This demonstrates that a composer's intentions cannot ultimately be considered to exercise sovereignty over the meaningful acts that a piece performs, which instead need to be ratified by its audience. Beil's discussion of Die Zwei's reception suggests that this ratification did not consistently take place.

[6.2.9] A critical attitude that takes the contents of pieces as their primary critical analytic is a deeply ingrained fixture within the attitudes of highly trained European New Music audiences of composers like Beil. With some pessimism, he reflects: "It is very difficult for trained listeners to react to music outside of their customary routines. This means that New Music, a music that was originally meant to stimulate reflection on music, is now preventing that very reflection among some of its specialists. A composition is listened to purely in terms of examining its material and structure." (Beil 2012, 12) This contextual feature stands in the way of Beil's idea of hearing the act of quotation above the content and structure of the quotation. The prevalence of the contentoriented critical perspective amounts to what we might call an "infelicity condition" (riffing on Austin's "felicity conditions") to describe those contextual conditions that can prevent an utterance from being heard as imbued with a particular illocutionary act.

\subsection{Conjuration at the Keyboard: Peter Ablinger's Talking Piano}

[6.3.1] Conceptualist composer Peter Ablinger's Quadraturen III series features a number of works in which a computer-controlled player-piano reproduces recordings of speech at a piano keyboard. YouTube recordings of two of the most famous works are available at the following links: "A Letter from Schoenberg" (YouTube), and "Deus Cantando" (YouTube). "A Letter from Schoenberg" is based on a recording of Arnold Schoenberg angrily reading a letter to Goddard Lieberson, then an executive at Columbia records. "Deus Cantando" is based on a recording of a child reading the Declaration of the International Environmental Criminal Court, written by activist/artist Adolfo Pérez Esquivel and the 14th Dalai Lama. As G. Douglass Barrett $(2009,2016)$ describes, these pieces vacillate between piano music, and speech-recordings: hearing the pieces with the text makes the speech readily audible and listening without them turns them into cacophonous and fragmentary piano music. Like a musical particle-wave duality, the manner of observation appears to change the phenomenon being heard.

[6.3.2] These pieces could be considered a conceptual extension of Ablinger's Voices and Piano series, in which some of the pitch content of recordings of famous speakers is transcribed for a live pianist accompanied by the original recording. Ablinger refers to Voices and Piano as a song-cycle of sorts, but he clarifies, "the piano part is not really accompanying the voices. . . The piano part is the temporal and spectral scan of the respective voice, something like a coarse gridded photograph." (http://ablinger.mur.at/voices_and_piano.html). In "A Letter from Schoenberg" and "Deus Cantando," Ablinger extends this logic and uses the enhanced capabilities of the playerpiano mechanism to create a sonic image at a higher resolution than a human performer could. In these pieces, the sound of the piano obeys certain constative logics: it points to the speaker, and it bears an iconic relation (a semiotic relation of resemblance) to the sound of the recorded voice. It also points to technologies of sound reproduction. The sound of the piano in the Quadraturen III pieces and the Voices and Piano series certainly involves the transmission of pre-given contents.

[6.3.3] But the talking piano pieces have an additional quality that the Voices and Piano series does not quite share. In addition to various constative tasks, these pieces reproduce the voice in ways that are startling, and perhaps even chilling or ghostly. "A Letter from Schoenberg" has an unsettling, paranormal quality that we might liken to being screamed at by a banshee. With the enhanced audibility and legibility of "Deus Cantando," it is possible to make out parts of the speech without the accompanying subtitles. Ablinger's vast personal website also affirms these 
quasi-supernatural qualities, the haunted uncanny in these pieces: "The sudden comprehensibility of single words, whenever the piano becomes the faithful representation of language, equally has the effect of a phantom's abrupt appearance: the close up reality of the voice is a ghostly apparition" (quoted from Mello 2010 on Ablinger's website). This characterization exposes a fault line between constative representation through pianistic sound and the irruption of a phantom presence appearing as a result of it. ${ }^{(51)}$

[6.3.4] These works incorporate a wondrous rupture: the piano, normally utterly unsuited to this task, begins to speak. The source of the vocal sound is thus underdetermined: Ablinger's talking piano pieces incite a perplexity as to how it is that vocal sound could be coming from a piano. I mention these qualities of rupture, the apparitional, perplexity, and wonder because they can be easily adduced as evidence for the non-semiotic excess of music and its sensuous, visceral impact, its ineffability, its numinous (and noumenal) powers. However, concepts of performative utterance and related semiotic theory provide resources that enable us to better understand the efficacy of Ablinger's talking piano pieces in a more precise analytical metalanguage than an appeal to ineffability. The piano's sound functions like a performative speech-act of conjuration, making manifest a sense of apparitional, spectral presences that speak through the piano. ${ }^{(52)}$ The literal absence of the voice's actual speaker clears a space for a different kind of origin: a ghost-like virtual entity imputed as a causal agent, to assimilate the sound of the voice with its seemingly unlikely site of production in the piano. ${ }^{(53)}$ As Brian Kane demonstrates in his work on acousmatic sound, sounds from underdetermined or mysterious sources "encourage the imaginative projection of a sonic body" $(2014,8)$.

[6.3.5] The early history of sound recording is also marked by the figure of this kind of apparitional presence. A 1902 advertisement (Example 10) for the Edison phonograph features a small boy seated before the device, gaze transfixed on it, as he wields a small hatchet high above his head as though to break it open (Brady 1999, 35). A small caption reads, "Looking for the band," as though the boy is looking for a group of miniaturized musicians inhabiting the machine. The Victor company's logo for its gramophone features the famous Nipper the dog staring curiously into the horn of the machine, supposedly listening for the voice of his deceased master (Example 11). The company's famous tagline, "his master's voice," suggests that Nipper wonders if his deceased owner has somehow materialized inside the horn or cabinet of the gramophone. Both images rely on a notion that exceeds and overfills mere sonic fidelity or correspondence. Both Nipper and the hatchet-wielding boy seem to posit an entity inside the machine that accounts for the sounds they hear as a rationalization strategy. Paradoxically, this entity is also conjured by what is heard: produced and created by the sound, yet also standing as that which is thought to produce and create the sound. Literary scholar Steven Connor, analyzing ventriloquism, explains: "Human beings in many different cultural settings find the experience of a sourceless sound uncomfortable. ... it is we who assign voices to objects; phenomenologically the fact that an unassigned voice must always imply a body means that it will always partly supply it as well" $(2000,35)$. This proclivity to supply what Kane calls the sonic body is what "ratifies" and enables the effect.

[6.3.6] Benjamin Lee describes a similar conjuration in terms of Austinian performativity in his discussion of the Declaration of Independence, arguing that "We hold these truths to be selfevident" helps to constitute and inaugurate the very "We" that the document otherwise presupposes as the collective agency that underwrites its power $(1997,321-45)$. There is a foundational paradox in the Declaration of Independence: it speaks on behalf of "the people," but they do not exist as such before the signing of the very document that presupposes them. The signers of the Declaration lack the authority to sign until after they have signed. The performative logic of the Declaration's "We" lies in both a constative reference to the "We" that underwrites its efficacy and authority, and, simultaneously, in a performative creation of that very "We" brought into being by the signing of the Declaration. ${ }^{(54)}$

[6.3.7] In Ablinger's talking piano pieces, there is a similar interplay of a performative, entailing logic, and a constative, referential logic. "A Letter from Schoenberg" and "Deus Cantando" point to the content of the recordings they are based on: there is a degree of sonic fidelity to their source recordings and the events of speaking they capture. But these pieces are also effective within context in a $\mathrm{P}_{2}$-performative manner: they causally entail and conjure a sense of the presence of a 
ghost-like sonic agent who speaks through the piano- an effect that could not arise were it not for the constative fidelity of the piano's sound to that of human voices. Wondrous, strange, and even ineffable though they may be, these effects are also semiotic - both performative and constative-in important ways. As Derrida writes of the Declaration of Independence (but in terms that generalize well): "This obscurity, this undecidability between, let's say, a performative structure and a constative structure, is required to produce the sought-after effect" $(1986,9)$.

\section{Taking Stock of Things}

[7.1.1] Above all, this essay is an invitation to set down momentarily a certain tool we are accustomed to wielding as part of our sense-making circumspection toward the sounding, musicking world. That tool is the conceptual framework underwritten by meaning-as-mapping. I offer an encouragement to apply a different set of conceptual tools to the task of registering meaning in musical sound and sonic environments, these being speech-act theory and theories of performative utterance. My argument is that these tools-adapted from linguistics and language philosophy, and qualified as necessary to suit the translation out of linguistic thinking and into music studies - allow us to more powerfully think musical and sonic meaning. These tools ground the inquiry into musical and sonic meaning in the actions and pressures produced by music and sound upon their contexts in analogy to verbal utterance.

[7.1.2] It would be possible to object to the preceding as a critique of meaning-as-mapping that makes its intervention by identifying yet more mappings between musical utterances and illocutionary acts. "You've sketched out the problems with meaning-as-mapping," this critic might respond, "but doesn't this intervention work by identifying mappings, thereby perpetuating the very structure of thought that you argue against?" To this criticism, the proper response would be that interpreting this project as a project of mapping music and sound to various illocutionary forces is not demonstrably false per se, but it amounts to wielding the conceptual tool of meaningas-mapping once again as the primary sense-making apparatus, this time as the apparatus for parsing the theoretical claims presented here. Or, "if you say that I am still doing mappings, then you are still doing mappings." The invitation I make is to set that tool aside and to wield another tool: not meaning-as-mapping, but instead an illocutionary seismograph of sorts - a style of thought that can become handy in registering the pressures, wave fronts, and undulations great or small that music and sound apply to their contexts, which may then meaningfully affect us thereby.

[7.1.3] When we interpret music as communication or utterance, the most robust perspective from which to do so is one that understands utterances as tools or equipment, handy for creating actions and producing effects. ${ }^{(55)}$ But when we become theoretically appreciative of the "handiness" and efficacy of music as utterance (in view of the actions it can perform), we also disrupt its ordinary condition of operation upon us. As Graham Harman, one originator of the emergent philosophical area of object-oriented ontology, writes concerning tools and equipment: "It is the nature of toolbeing to recede from every view. In the strict sense, we can never know just what equipment is. Like the giant squids of the Marianas Trench, tool-beings can be seen only after they have washed up dead on the shore, no longer immersed in the sincerity of their withdrawn reality" $(2002,4-5)$.

[7.1.4] Interpreting the meanings/contents that are disclosed in particular works, practices or repertories is simply one way of catching music in the act of doing things with tones/rhythms/harmonies/motifs (and so forth), one way of entering into concernful relationships with music and the ways it affects our goals, concerns and activities. The $\mathrm{P}_{2}$-performativity of

music is, by this account, not something "extra" on top of an abstract nucleus of the specificity of musical structures or the purported messages they bear. Instead, it designates the ways in which they are imbricated within the everydayness of the ways we use music in our practices.

Christopher Small, in his discussion of "musicking" as a praxis rather than as a thing, writes that "the apparent thing 'music' is a figment, an abstraction of the action, whose reality [as a thing] vanishes as soon as we examine it at all closely" $(1998,2)$. Likewise, equating musical meaning with the (referential) meanings found in music is to conjure a figment in place of the condition of its possibility. When speaking of musical meaning in either referentialist terms or in expressivist 
terms that center on the emotional/affective states that music can conjure in us, we would do well to remember that both of these are durable traces of acts, which vanish.

[7.1.5] This neither refutes nor diminishes previous studies of what and how music means in the logic of constativity; it simply draws a wider circle around certain familiar questions about the music-language metaphor and what music discloses. Furthermore, this argument is not a claim that all musical questions nor all questions about the effects of music are reducible to questions about musical meaning. Music is not exhausted by its meaningful aspects. Inquiries into performance, the body, the materiality of music making, its sensuous force, and so on, need not necessarily be considered as inquiries into meaning, but many of them may interact with the conceptions of meaning advanced in this essay.

[7.1.6] We often describe music as, if anything at all, expressive, from the Latin "expressio:" literally, a pressing out, a projection tethering inner content to outer form, a revealing of that which is hidden. Expression itself, however, is a weak basis on which to ground our understanding of that manifold which we use the term to name. For us to claim that music can express anything at all is already for us to catch music in the act of "doing things," to repeat one last time Austin's turn of phrase. The Austinian concept of performative utterance and the tradition of ordinary language philosophy offer two things to musical studies. One is a more robust basis for the music-language analogy: the opportunity to see music's meanings in an actional light and to see the ways that music as utterance applies pressure to its situations and contexts. The second is a rejoinder to recent avowals of musical ineffability: agreement that music's vibrant action-character and efficacy may well be beyond the representational, but in turn the suggestion that these may lie at least partly within an expanded notion of the semiotic capacities of music as utterance. Ultimately, this essay is a word of caution: simply, a demonstration of theoretical principles that enjoin us to motivate turns into or away from language on more reflective grounds.

Andrew J. Chung

Yale University

Department of Music

55 Bishop St., Apt. A

New Haven, CT 06511

andrew.j.chung@yale.edu

\section{Works Cited}

Abbate, Carolyn. 2004. “Music-Drastic or Gnostic?” Critical Inquiry 30 (3): 505-36.

Adams, Kyle. 2015. "What Did Danger Mouse Do? The Grey Album and Musical Composition in Configurable Culture." Music Theory Spectrum 37 (1): 7-24.

Adorno, T. W. 1978. “On the Social Situation of Music.” Télos 1978 (35): 128-64.

Agawu, V. Kofi. 1991. Playing with Signs: A Semiotic Interpretation of Classic Music. Princeton University Press.

2000. Music as Discourse: Semiotic Adventures in Romantic Music. Oxford University Press.

Allanbrook, Wye J. 1992. "Two Threads Through the Labyrinth." In Convention in Eighteenth-and Nineteenth-Century Music: Essays in Honor of Leonard G. Ratner, eds. Allanbrook, Janet M. Levy, and William P. Mahrt, 125-71. Pendragon.

Almén, Byron. 2008. A Theory of Musical Narrative. Indiana University Press.

Alston, William P. 2000. Illocutionary Acts and Sentence Meaning. Cornell University Press.

Austin, J. L. [1962] 1975. How to Do Things with Words, eds. J. O. Urmson and Marina Sbisà. 2nd edition. Harvard University Press.

Bach, Kent, and Robert M. Harnish. 1979. Linguistic Communication and Speech Acts. MIT Press. 
Barad, Karen. 2003. "Posthumanist Performativity: Toward an Understanding of How Matter Comes to Matter." Signs 28 (3): 801-31.

Barrett, G. Douglas. 2009. "Between Noise and Language: The Sound Installations and Music of Peter Ablinger." Mosaic: An Interdisciplinary and Critical Journal 42 (4): 147-64.

. 2016. "Music to the Letter: Noise, Language, and the Letter from Schoenberg." In After Sound: Towards a Critical Music, 96-116. Bloomsbury.

Bauer, Nancy. 2015. How to Do Things with Pornography. Harvard University Press.

Beil, Michael. 2011. “AV-Music and Video.” eContact! 13 (2). http://econtact.ca/13_2/beil_AV.html 2012. "Material Shift." In Musical Material Today, eds. Claus-Steffen Mahnkopf, Frank Cox, and Wolfram Schurig, 9-20. Wolke Verlag.

Bierwisch, Manfred. 1980. "Semantic Structure and Illocutionary Force." In Speech Act Theory and Pragmatics, eds. John R. Searle, Ferenc Kiefer, and Bierwisch, 1-35. Springer.

Bolter, Jay David, and Richard Grusin. 1998. Remediation: Understanding New Media. MIT Press.

Boone, Christine. 2013. "Mashing: Toward a Typology of Recycled Music.” Music Theory Online 19 (3). http://mtosmt.org/issues/mto.13.19.3/mto.13.19.3.boone.html

Borges, Jorge Luis. 1999. "Pierre Menard, Author of the Quixote." In Collected Fictions, trans. Andrew Hurley, 88-95. Penguin Books.

Bourdieu, Pierre. 1991. Language and Symbolic Power. Edited by John Thompson. Translated by Gino Raymond and Matthew Adamson. Harvard University Press.

Bower, Calvin. 2002. “The Transmission of Ancient Music Theory into the Middle Ages.” In Cambridge History of Western Music Theory, ed. Thomas Christensen, 136-67. Cambridge University Press.

Brady, Erika. 1999. A Spiral Way: How the Phonograph Changed Ethnography. University Press of Mississippi.

Brøvig-Hanssen, Ragnhild, and Paul Harkins. 2012. “Contextual Incongruity and Musical Congruity: The Aesthetics and Humour of Mash-Ups." Popular Music 31 (1): 87-104.

Brower, Candace. 2000. "A Cognitive Theory of Musical Meaning." Journal of Music Theory 44 (2): 32379.

Butler, Judith. 1997. Excitable Speech: A Politics of the Performative. Routledge. 1999. “Performativity's Social Magic.” In Bourdieu: A Critical Reader, ed. Richard Shusterman, 113-28. Blackwell. . 2002. "Afterword." In The Scandal of the Speaking Body: Don Juan with J. L. Austin, or Seduction in Two Languages, by Shoshana Felman, 113-23. Stanford University Press.

Certeau, Michel de. 1984. The Practice of Everyday Life. University of California Press.

Chion, Michel. 1994. Audio-Vision: Sound on Screen. Columbia University Press.

Coker, Wilson. 1972. Music E Meaning: A Theoretical Introduction to Musical Aesthetics. Free Press.

Connor, Steven. 2000. ???

Cook, Nicholas. 1999. "Analysing Performance and Performing Analysis." In Rethinking Music, eds. Nicholas Cook and Mark Everist, 239-61. Oxford University Press.

Cooke, Deryck. 1959. The Language of Music. Oxford University Press. 
Cornfeld, Li. 2012. "How to Do Things with Magic Words: The Scandal of the Spell-Casting Body." In Hermione Granger Saves the World: Essays on the Feminist Heroine of Hogwarts, ed. Christopher E. Bell, 125-41. McFarland.

Culpeper, Jonathan, and Elena Semino. 2000. "Constructing Witches and Spells: Speech Acts and Activity Types in Early Modern England." Journal of Historical Pragmatics 1: 97-116.

Cumming, Naomi. 2001. The Sonic Self: Musical Subjectivity and Signification. Indiana University Press.

Cusick, Suzanne G. 2008. “Musicology, Torture, Repair.” Radical Musicology 3. http://radicalmusicology.org.uk/2008/Cusick.htm

Cutler, Chris. [1994] 2004. "Plunderphonia." In Audio Culture: Readings in Modern Music, eds. Christoph Cox and Daniel Warner, 138-56. Continuum.

Daughtry, J. Martin. 2015. Listening to War: Sound, Music, Trauma, and Survival in Wartime Iraq. Oxford University Press.

Davies, Stephen. 2011. Musical Understandings and Other Essays on the Philosophy of Music. Oxford University Press.

Deleuze, Gilles. 1988. Bergsonism. Translated by Hugh Tomlinson and Barbara Habberjam. Zone Books.

DeNora, Tia. 1986. "How Is Extra-Musical Meaning Possible? Music as a Place and Space for 'Work."” Sociological Theory 4 (1): 84-94.

2002. “Music into Action: Performing Gender on the Viennese Concert Stage, 17901810." Poetics 30 (1): 19-33.

Derrida, Jacques. 1986. “Declarations of Independence.” New Political Science 7: 7-15.

. [1972] 1988. "Signature, Event Context." In Limited Inc, ed. Gerald Graff, trans. Jeffrey Mehlman and Samuel Weber, 1-24. Northwestern University Press.

Duncan, Michelle. 2004. "The Operatic Scandal of the Singing Body: Voice, Presence, Performativity." Cambridge Opera Journal 16 (3): 283-306.

Dyson, Frances. 2009. Sounding New Media: Immersion and Embodiment in the Arts and Culture. University of California Press.

Eidsheim, Nina Sun. 2015. Sensing Sound: Singing and Listening as Vibrational Practice. Duke University Press.

Felman, Shoshana. [1983] 2002. The Scandal of the Speaking Body: Don Juan with J. L. Austin, or Seduction in Two Languages. Stanford University Press.

Finnegan, Ruth. 1969. "How to Do Things with Words: Performative Utterances Among the Limba of Sierra Leone." Man 4 (4): 537-52.

Furberg, Mats. 1967. “Meaning and Illocutionary Force." In Symposium on J. L. Austin, ed. K. T. Fann, 445-68. Routledge.

Gallope, Michael, Brian Kane, Steven Rings, James Hepokoski, Judy Lochhead, Michael J. Puri, and James R. Currie. 2012. “Vladimir Jankélévitch's Philosophy of Music.” Journal of the American Musicological Society 65 (1): 215-56.

Gallope, Michael. 2017. Deep Refrains: Music, Philosophy, and the Ineffable. University of Chicago Press.

Gawboy, Anna. 2009. “The Wheatstone Concertina and Symmetrical Arrangements of Tonal Space." Journal of Music Theory 53 (2): 163-90.

Goffman, Erving. 1981. Forms of Talk. University of Pennsylvania Press. 
Gu, Yueguo. 1993. “The Impasse of Perlocution.” Journal of Pragmatics 20 (5): 405-32.

Gumbrecht, Hans Ulrich. 2003. Production of Presence: What Meaning Cannot Convey. Stanford University Press.

Gumperz, John J. 1982. Discourse Strategies. Cambridge University Press.

Gunkel, David J. 2008. "Rethinking the Digital Remix: Mash-ups and the Metaphysics of Sound Recording." Popular Music and Society 31 (4): 489-510.

. 2012. "What Does It Matter Who Is Speaking? Authorship, Authority, and the Mashup." Popular Music and Society 35 (1): 71-91.

Hanslick, Eduard. [1854] 1986. On the Musically Beautiful: A Contribution Towards the Revision of the Aesthetics of Music. Translated by Geoffrey Payzant. Hackett Publishing Company.

Harman, Graham. 2002. Tool Being: Heidegger and the Metaphysics of Objects. Open Court.

Haraway, Donna J. 1988. "Situated Knowledges: The Science Question in Feminism and the Privilege of Partial Knowledges." Feminist Studies 14 (3): 575-99

Hatten, Robert S. 1994. Musical Meaning in Beethoven: Markedness, Correlation, and Interpretation. Indiana University Press.

- 2004. Interpreting Musical Gestures, Topics, and Tropes: Mozart, Beethoven, Schubert. Indiana University Press.

Martin Heidegger. [1927] 1962. Heidegger, Martin. [1927] 1962. Being and Time. Translated by John Macquarrie and Edward Robinson. Blackwell.

. [1954] 1968. What is Called Thinking? Translated by Fred D. Wieck and J. Glenn Gray.

Harper \& Row.

Hepokoski, James. 1991. “The Dahlhaus Project and its Extramusical Sources.” 19th-Century Music 14 (3): 221-46.

Ivanovitch, Roman. 2008. "Showing Off: Variation in the Display Episodes of Mozart's Piano Concertos." Journal of Music Theory 52 (2): 181-218.

Jackson, Shannon. 2004. Professing Performance: Theatre in the Academy from Philology to Performativity. Cambridge University Press.

Jankélévitch, Vladimir. [1959] 1996. “Do Not Listen to What They Say, Look at What They Do.”

Translated by Ann Hobart. Critical Inquiry 22 (3): 549-51.

_- 2003. Music and the Ineffable. Translated by Carolyn Abbate. Princeton University Press.

Kane, Brian. 2014. Sound Unseen. Oxford University Press.

Kerman, Joseph. 1980. "How We Got into Analysis, and How to Get out." Critical Inquiry 7 (2): 31131.

Kivy, Peter. 1980. The Corded Shell: Reflections on Musical Expression. Princeton University Press.

Press. 1984 . Sound and Semblance: Reflections on Musical Representation. Princeton University

2009. Antithetical Arts: On the Ancient Quarrel Between Literature and Music. Oxford University Press.

Kramer, Lawrence. 1990. Music as Cultural Practice, 1800-1900. University of California Press. 
Kubicki, Judith Marie. 1999. “Interpreting Taizé Prayer in Light of J. L. Austin's Performative Language Theory." In Liturgical Music as Ritual Symbol: A Case Study of Jacques Berthier's Taizé Music, 147-60. Peeters Publishers.

Lee, Benjamin. 1997. Talking Heads: Language, Metalanguage, and the Semiotics of Subjectivity. Duke University Press Books.

Lerdahl, Fred, and Ray S. Jackendoff. 1983. A Generative Theory of Tonal Music. MIT Press.

Levinson, Jerrold. 1981. "Truth in Music.” The Journal of Aesthetics and Art Criticism 40 (2): 131-44.

Lévi-Strauss, Claude. 1987. Introduction to the Work of Marcel Mauss. Taylor \& Francis.

Lewin, David. 1987. Generalized Musical Intervals and Transformations. Yale University Press.

Lewis, David. 1970. “General Semantics.” Synthese 22 (1/2): 18-67.

Lidov, David. 2004. Is Language a Music? Writings on Musical Form and Signification. Indiana University Press.

London, Justin. 1996. "Musical and Linguistic Speech Acts." The Journal of Aesthetics and Art Criticism 54 (1): 49-64.

Lucier, Alvin. 1995. Reflections: Interviews, Scores, Writings. MusikTexte.

Madrid, Alejandro. 2009. "Why Music and Performance Studies? Why Now?: An Introduction to the Special Issue." TRANS-Transcultural Music Review 13.

https://www.sibetrans.com/trans/articulo/1/why-music-and-performance-stud

Marcu, Daniel. 2000. “Perlocutions: The Achilles' Heel of Speech Act Theory." Journal of Pragmatics 32 (12): 1719-41.

Mattheson, Johann, and Hans Lenneberg. 1958. "Johann Mattheson on Affect and Rhetoric in Music (I)." Journal of Music Theory 2 (1): 47-84.

McClary, Susan. 1991. Feminine Endings: Music, Gender, and Sexuality. University of Minnesota Press.

1994. “Constructions of Subjectivity in Schubert's Music." In Queering the Pitch: The New Gay and Lesbian Musicology, eds. Philip Brett, Elizabeth Wood, and Gary C. Thomas, 205-34. Routledge.

McCreless, Patrick. 1991. “The Hermeneutic Sentence and Other Literary Models for Tonal Closure." Indiana Theory Review 12: 35-73.

Medina, José. 2006. Speaking from Elsewhere: A New Contextualist Perspective on Meaning, Identity, and Discursive Agency. SUNY Press.

Mello, Chico. 2010. Mimesis und musikalisches Konstruktion. Shaker Verlag.

Meyer, Leonard B. 1956. Emotion and Meaning in Music. University of Chicago Press.

Moi, Toril. 2017. Revolution of the Ordinary: Literary Studies after Wittgenstein, Austin, and Cavell. University of Chicago Press.

Monelle, Raymond. 1992. Linguistics and Semiotics in Music. Routledge.

2000. The Sense of Music. Princeton University Press.

2006. The Musical Topic: Hunt, Military and Pastoral. Indiana University Press.

Oswald, John. [1987] 2004. “Bettered by the Borrower: The Ethics of Musical Debt.” In Audio Culture: Readings in Modern Music, eds. Christoph Cox and Daniel Warner, 131-37. Continuum. 
Parker, Andrew, and Eve Kosofsky Sedgwick, eds. 1995. Performativity and Performance. Routledge.

Pearsall, Edward. 2006. "Anti-Teleological Art: Articulating Meaning Through Silence." In Approaches to Meaning in Music, eds. Byron Almén and Edward Pearsall, 41-61. Indiana University Press.

Phelan, Peggy. 1993. Unmarked: The Politics of Performance. Routledge.

Pöggeler, Otto. 1972. “Heidegger's Topology of Being.” In On Heidegger and Language. Edited and translated by Joseph J. Kockelmans. Northwestern University Press.

Reddy, Michael J. 1979. "The Conduit Metaphor." In Metaphor and Thought, ed. by Andrew Ortony, 284-310. Cambridge University Press.

Risi, Clemens. 2011. “Opera in Performance-In Search of New Analytical Approaches.” The Opera Quarterly 27 (2): 283-95.

Robinson, Douglas. 2005. Introducing Performative Pragmatics. Routledge.

Rorty, Richard, ed. 1967. The Linguistic Turn: Essays in Philosophical Method. University of Chicago Press.

Rosaldo, Michelle Z. 1982. “The Things We Do with Words: Ilongot Speech Acts and Speech Act Theory in Philosophy." Language in Society 11 (2): 203-37.

Rubenstein, Mary-Jane. 2012. Strange Wonder: The Closure of Metaphysics and the Opening of Awe. Columbia University Press.

Rumph, Stephen. 2011. Mozart and Enlightenment Semiotics. University of California Press.

. 2015. "Fauré and the Effable: Theatricality, Reflection, and Semiosis in the Mélodies." Journal of the American Musicological Society 68 (3): 497-558.

Rupprecht, Philip. 2001. Britten's Musical Language. Cambridge University Press.

Sartre, Jean-Paul. 1988. "What Is Literature?" and Other Essays. Harvard University Press.

Saussure, Ferdinand de. [1916] 1998. Course in General Linguistics. Edited and translated by Roy Harris. Open Court.

Schechner, Richard. 1985. Between Theater and Anthropology. University of Pennsylvania Press.

Searle, John R. 1970. Speech Acts: An Essay in the Philosophy of Language. Cambridge University Press.

Silverstein, Michael. 1976. "Shifters, Linguistic Categories, and Cultural Description." In Meaning in Anthropology, eds. Keith H. Basso and Henry A. Selby, 11-55. University of New Mexico Press.

2003. "Indexical Order and the Dialectics of Sociolinguistic Life." Language E Communication 23: 193-229.

. 2014. “Translatability and the Uses of Standardisation." Working Paper. Tillburg Papers in Cultural Studies.

Small, Christopher. 1998. Musicking: The Meanings of Performing and Listening. Wesleyan University Press.

Stokes, Martin. 1994. Ethnicity, Identity and Music: The Musical Construction of Place. Berg Publishers.

Subotnik, Rose Rosengard. 1995. Deconstructive Variations: Music and Reason in Western Society. University of Minnesota Press.

Swinkin, Jeffrey. 2016. Performative Analysis: Reimagining Music Theory for Performance. University of Rochester Press.

Sykes, Jim. 2018. The Musical Gift: Sonic Generosity in Post-War Sri Lanka. Oxford University Press. 
Tagg, Philip. 1987. “Musicology and the Semiotics of Popular Music.” Semiotica 66 (1/3): 279-98.

Tambiah, S. J. 1968. “The Magical Power of Words.” Man 3 (2): 175-208.

Tarasti, Eero. 2001. Existential Semiotics. Indiana University Press.

Tomlinson, Gary. 2007. The Singing of the New World: Indigenous Voice in the Era of European Contact. Cambridge University Press.

Treitler, Leo. 2011. Reflections on Musical Meaning and Its Representations. Indiana University Press.

Tunstall, Patricia. 1979. "Structuralism and Musicology: An Overview." Current Musicology 27: 51-64.

Turino, Thomas. 2014. "Peircean Thought As Core Theory For A Phenomenological

Ethnomusicology." Ethnomusicology 58 (2): 185-220.

Turner, Ken, ed. 1999. The Semantics/Pragmatics Interface from Different Points of View. Elsevier.

Turner, Victor. 1982. From Ritual to Theatre: The Human Seriousness of Play. PAJ Publications.

Wen, Eric. 2016. "Schubert's Wiegenlied: The Andante Sostenuto from the Piano Sonata in Bb D. 960." In Schubert's Late Music: History, Theory, Style, eds. Lorraine Byrne Bodley and Julian Horton, 13448. Cambridge University Press.

Witkin, Robert W. 2003. Adorno on Popular Culture. Routledge.

Wittgenstein, Ludwig. [1953] 1958. Philosophical Investigations. Translated by G. E. M. Anscombe. 3rd edition. Macmillan.

Wong, Deborah. 2001. Sounding the Center: History and Aesthetics in Thai Buddhist Performance. University of Chicago Press.

Zbikowski, Lawrence. 2002. Conceptualizing Music: Cognitive Structure, Theory, and Analysis. Oxford University Press.

Zhmud, Leonid. 2012. Pythagoras and the Early Pythagoreans. Oxford University Press.

\section{Footnotes}

* This paper draws on the introduction and first chapter of my dissertation, Music as Performative Utterance: Towards a Unified Theory of Musical Meaning with Applications in 21st-Century Works and Social Life. Versions of this paper was presented at the AMS-Pacific Southwest chapter Fall 2017 meeting, the 2018 meeting of Music Theory Southeast, and the Open Space forum at the 2018 Darmstadt Summer Courses. I would like especially to thank Patrick McCreless, Brian Kane, Gundula Kreuzer, Marta Figlerowicz, and the anonymous reviewers for their input on this manuscript.

Return to text

1. The term musicking, a once antiquated term, has come into our lexicon afresh in recent years, following Christopher Small's (1998) revitalization of the term. He writes to emphasize the processual character of music up and over against its object character: "There is no such thing as music. Music is not a thing at all but an activity, something that people do" (2).

Return to text

2. In this essay, utterance shall be defined minimally, broadly, and intuitively as a unit of music actually taking place or being imagined to take place in performance, audiation, imagined performance, the audiation we imagine a composer doing, etc. For any musical object to count as an utterance or as part of one, the prerequisite will simply be the perspectival attitude that it is taking place or has taken place in a real or imagined context of performance or audiation. This essay explores music as utterance in contrast to music as language or text because the latter two models connote bounded abstract systems that do not presuppose any necessary connection to ongoing forms of praxis (think of "dead" languages, or texts that nobody reads), while utterance is 
unthinkable without its involvement in ongoing forms of praxis. The utterance model developed here, however, generalizes well to the written.

Return to text

3. In this connection, we should also note important predecessors in Carolyn Abbate's (2004) controversial and generative work concerning a "drastic" rather than "gnostic" idea of musical study, and philosopher Hans Ulrich Gumbrecht's (2003) Production of Presence: What Meaning Cannot Convey.

Return to text

4. The material effects of vibration may be as extreme as the use of sound cannons in practices of militarized policing. For reflections on these and related violent uses of music, see Cusick 2008 and Daughtry 2015.

Return to text

5. The linguistic turn has its origins in debates concerning the philosophy of language (see Rorty 1967) in which one prominent position sought to conceive of basic philosophical problems as problems that arose fundamentally in how ordinary language was used to communicate about those philosophical questions and the answers to them. Musical semiotics (see note 40) eventually grew out of these concerns, along with a diversity of humanistic and social science fields that began to apply structuralist literary methods to the study of social and aesthetic phenomena. These fields began reading cultural phenomena as "texts" structured according to abstract systems of differences ("languages"). Other related interdisciplinary connections brought musical studies into dialogue with Chomskyan ideas of generative grammar (e.g. Lerdahl and Jackendoff 1983), poststructuralist cultural critique (e.g. Subotnik 1995), with Barthesian literary criticism (e.g. McCreless 1991), theories of metaphor (e.g. Zbikowski 2002), Gadamerian hermeneutics and reader-response theory (see Hepokoski 1991), and so forth.

Return to text

6. Signifier and signified are terms most commonly associated with linguist and semiologist Ferdinand de Saussure ([1916] 1998). Saussure's position is in fact considerably more complex than the simple signifier-signified relation that his Course in General Linguistics is so often reduced to. For Saussure, a signifier signifies in absentia, in virtue of the first fact that it does not signify the manifold things that the other signifiers do. The positive mapping between sign and designatum is a conceptual apparatus far older than Saussure (one that Ludwig Wittgenstein ([1953] 1958) in the Philosophical Investigations, for instance, attributes to St. Augustine), but it has come to be associated with his terminology. This essay works to move away from Saussure's orbit by focusing on theories of sign use (what he called parole) instead of what he considered to be the proper seat of study: the abstract system of signs (what he called langue).

Return to text

7. Adorno qualifies that music's critical-theoretic function is not to be found primarily in commenting explicitly on society propositionally, nor in predicating about society as a form of outright discursive content (see Witkin 2003, 87). Adorno does, however, affirm a formal mapping between the problems immanent in music's structuration and the problems facing society. This idea served as one of the conceptual underpinnings for some of the hermeneutic work associated with the New Musicology. Susan McClary for instance, reflects that "in his hands, the presumably nonrepresentational instrumental music of the canon becomes the most sensitive social barometer in all of culture" $(1991,28)$.

Return to text

8. For modern-day iterations of the claim that music is a system of signifiers without signifieds, see, for instance, Lidov 2004 or Tunstall 1979. The idea of signifiers without signifieds, and the "floating signifier," originates with the work of Claude Lévi-Strauss (1987, 63-64).

Return to text

9. Abbate glosses the position espoused by Jankélévitch that music has "broad shoulders" to support ascriptions of meaning to it since it "unleashes meaning in high multiples" $(2004,516)$. Return to text 
10. Jankélévitch, for instance, invokes a version of this dichotomy: "Saying is an atrophied version of Doing - miscarried Doing" $(2003,80)$. This dichotomy is reflected in the title of another of Jankélévitch's essays: “Do Not Listen to What They Say, Look at What They Do" ([1959] 1996).

Return to text

11. Treitler enumerates some characteristic lines of inquiry that presuppose the thinking that Meyer calls referentialism: "Is it that infused meanings are supposed to have been held by the contemporaries of the works or newly discovered by the interpreters? Are they held to be immanent to the works? Are they claimed to be conveyed through the experience of the works, which they inform, or are they deduced from the works or from other sources?" $(2011, x i i)$. Return to text

12. The concept of handiness is inspired by Heidegger's ([1927] 1962) technical term ready-to-hand, which describes how entities gain their authentic identities in the encounters we have with them in using and relating to them as though they are tools. The term present-at-hand, by contrast, describes how we encounter entities inauthentically when we exercise theoretical attitudes based on documenting their properties and reifying them under particular names and identities to exercise mastery over them.

Return to text

13. This way of entering into questions concerning the problem of musical meaning is modelled after the strategy that Heidegger ([1927] 1962) takes in his Being and Time, which sought a new beginning for ontology, the study of being. Heidegger begins by pointing out that while philosophers since the pre-Socratics have asked many questions about being and made many propositions about being, the Western tradition had not answered the fundamental question: What is it to be? What is "is?"

Return to text

14. Technical definitions of "meaning" in linguistics and language philosophy often specify it as "literal meaning" or "null-context referential meaning," and the above is not necessarily a problem for those investigations, if meaning is to be circumscribed in this manner. However, I suspect that we typically have something broader in mind when investigating musical meaning, and we must therefore contend with the perplexity that resides within "what does 'meaning' mean?"

Return to text

15. Cf. Heidegger: "The achieving of phenomenological access to the entities which we encounter, consists rather in thrusting aside our interpretative tendencies, which keep thrusting themselves upon us and running along with us, and which conceal not only the phenomena of such 'concern,' but even more those entities themselves as encountered of their own accord in our concern with them" ([1927] 1962).

Return to text

16. These scholars demonstrate that understanding non-Western practices through the lens of Austinian theory is not necessarily conceptual colonialism or an attempt to bring practices of other peoples under the theoretical mastery of an Anglophone theory. Instead, they suggest that the musical practices of other cultures might make more apparent certain aspects of Western music making that have been occluded, aspects that Austinian theory is particularly suited to analyze. Return to text

17. Linguistic pragmatics investigates non-literal meanings and the interactions of meaningful units with features of context and aspects of how they are used. It remains a matter of considerable debate whether pragmatics is a supplement to semantics, or whether semantics arises out of pragmatics (see, for instance, Turner 1999).

Return to text

18. See David Lewis: "I distinguish two topics: first, the description of possible languages or grammars as abstract semantic systems whereby symbols are associated with aspects of the world; and, second, the description of the ... facts whereby a particular one of these abstract semantic systems is the one used by a person or population. Only confusion comes of mixing these two 
topics" $(1970,19)$.

Return to text

19. Speech-act is a coinage by Austin's student John Searle (1970).

Return to text

20. Similarly, Michel de Certeau suggests in The Practice of Everyday Life that the performative concept of speech-act theory might be applicable to phenomena beyond language: "The speech act is at the same time a use of language and an operation performed on it. We can attempt to apply this model to many non-linguistic operations" $(1984,32)$.

Return to text

21. Esprit Rude/Esprit Doux II does not state the AITC at this pitch-level.

Return to text

22. I thank the anonymous reviewers for pointing out this connection.

Return to text

23. Allanbrook 1992 identifies a succession of five topoi in the exposition of K. 332: the singing style, the learned style, the horn call topic, the so-called Sturm und Drang or tempesta topic, and the minuet topic.

Return to text

24. It is for this reason that Austin abandoned the performative-constative distinction midway through How to Do Things with Words in favor of the analysis of illocutionary forces. Austin, seeking mutually exclusive categories, found that the performative-constative distinction could not strictly separate its terms because the constative function of language was revealed to be simply one category of the performative function of language.

Return to text

25. Throughout this essay, illocutionary forces will be indicated in italics where appropriate. Return to text

26. As sociolinguist Erving Goffman (1983) qualifies, it is impossible to reduce felicity conditions to a science, to tabulate them exhaustively. Hence, it could be argued that pragmatic theories of meaning are destined to fail as theories because context cannot be theorized fully. But this is to dogmatically require the total systematization and calculability of contextual "language-external" factors in the same way that a theorist of "internal" features might wish to require of systems of syntactical coherence. It is profoundly artificial to attempt to bring "context" as a generality under full theoretical control as though we can ever stand outside of context to observe it and all of its possible implications abstractly as a totality.

Return to text

27. I thank the anonymous reviewers for this suggestion.

Return to text

28. Speech-acts and performative utterances are examples of Charles Sanders Peirce's indexical sign modality: signs which point to features of their context. As Silverstein $(2003,195)$ clarifies, indexical signs do not just point to pre-existing features of their context; they can also relate to their contexts by creating and causally entailing new features of context through their use. This is the semiotic basis for Austinian speech-act theory.

Return to text

29. It is for this reason that perlocutions have been deemed by some linguists and philosophers to be untheorizable, to stand outside a systematic treatment. See Gu 1993 and Marcu 2000.

Return to text

30. Incidentally, as Treitler (2011) notes about this letter, it also upends the traditional thinking in which language meaning is semantically precise, in favor of asserting an extraordinary (but unverbalizable) precision of musical meaning. Mendelssohn opines that language, through the 
infinitely variable circumstances of its use, can be as semantically polysemous as music is, anticipating similar suggestions from ordinary language philosophy in the twentieth century. Return to text

31. While the study of music as reference, representation, and disclosure arguably has its contemporary roots in Enlightenment semiotics (see Rumph 2011), thinking of music in terms of the effects that it wields is considerably older. Ideas that music is meaningful because it not only mimetically corresponds to but also excites the passions were widely discussed by Baroque-era musical thinkers René Descartes and Johannes Mattheson (Mattheson and Lenneberg 1958), though it is not clear that contemporaneous thinkers considered this work to concern musical meaning per se. These Baroque concepts are themselves descended from early Greek sources concerning the effects of different Greek modes upon the behaviors of individuals and populations (see Zhmud 2012 and Bower 2002).

Return to text

32. Linguists Kent Bach and Robert M. Harnish distinguish between "conventional" speech-acts, which are performed somewhat independently of speakers' intentions, and "communicative" speech-acts, which seem to require that the speaker "mean them" in some way (Bach and Harnish 1979). Anthropologist Michelle Z. Rosaldo (1982), on the other hand, suggests that even locating an analytical axis in the intentions behind speech-acts is conditioned by a Western idea of the speaking subject primarily as willful, self-determining individuals, rather than primarily as members of collective communities, an ideology that she argues more accurately reflects her ethnographic subjects in the Philippines.

Return to text

33. In this use-theoretic focus, Austin's work on the performative function of language, as a foundational intervention into language and sign meaning, echoes some of Heidegger's ([1927] 1962) thoughts on language in Being and Time. Philosopher James Edie explains that Heidegger recognizes that language might be "asserting, pointing out or stating something, but that there is another, more fundamental, field of linguistic usage involved in our 'concernful dealing with that which is.' This field of usage is expressed in such linguistic forms as requesting, wishing, commanding, and so on... This distinction becomes the even more encompassing distinction between the theoretical attitudes of consciousness (theoria). . . and the practical and 'concernful' attitudes (praxis)" (Pöggeler 1972, 139-40). This distinction maps onto and further defines Austin's constative (theoria) versus performative (praxis) distinction.

Return to text

34. As media theorists Jay Bolter and Richard Grusin (1998) describe, in a more or less Heideggerian argument, we have trouble seeing the features of the medium so long as they operate smoothly for us.

Return to text

35. Philosopher Otto Pöggeler summarizes: “Since Aristotle’s time philosophical speech has been one-sidedly determined from . . . assertion, not from request, question, and command also. In this way the pragmatic dimension of language is expelled from philosophical speech in favor of the semantic dimension and is relinquished to rhetoric" $(1972,143)$.

Return to text

36. Heidegger's late work, particularly the 1954 volume of lectures collected under the title What is Called Thinking? (Heidegger [1954] 1968) similarly propounds a view of language meaning that seeks to overcome "the dominance of ideational or representational thinking" (64) and the "relation between name and thing as the coordination [mapping] of two objects" (120), describing these frameworks as superficial (46). He instead emphasizes language and thought as forms of action and "handicraft" (23), and grounds meaning in an understanding of use and action (191). Heidegger plays on his title by discussing how things call for and beseech us to think thoughts, which call for and beseech us to comport ourselves to them. This text deeply investigates certain attitudes that motivate the present intervention into the discourse on musical meaning.

Return to text 
37. My aim is not to stake out a position against new materialist or affect-theoretic studies of music, for example, but simply to question the premise of motivating these programs of study from rejections of music-and-meaning and to challenge the assumptions made in framing music's purportedly non-signifying dimensions and its non-linguistic character.

Return to text

38. For a rigorous and textured account of musical ineffability and its affordances across a range of philosophical thought (including that of Jankélévitch), see Gallope 2017. While studies that vouch for the ineffable qualities of music typically define music in non-signifying, non-discursive terms, the argument I present is simply that semiotic categories of action and efficacy lie in excess of music's representational qualities. Part of what has typically been assigned to the category of the ineffable might not be so far from the orbit of signs and semiosis, although this is by no means to claim that the expanded understanding of music in terms of signs or utterance argued here exhausts the category of the ineffable and its withdrawn recesses.

Return to text

39. Silverstein offers a sketch of the history by which the semantico-referential view of language meaning became the prevailing doxa in the Western tradition's past millennium: with the Enlightenment's emphasis on "grammar and logic ... you [subsequently] think of semantics-the way language stands for things-as being truth-functional, and of course you get symbolic logic, you get semantic theories for almost everything and so on" $(2014,2)$.

Return to text

40. This is not to deny that many finer distinctions stand to be made within a broadly mappingbased theory of meaning. Peter Kivy $(1980,1984,2009)$, for instance, rigorously analyzes the differences between musical representation (of discursive ideas) and reference (to things, emotional states, etc.), and makes a distinction, clarifying that music does not express or beget the emotions attributed to it but is expressive of them. Notable philosophers of music like Kivy, Davies, and Levinson, however, tend to be committed to an understanding of meaning that I am working to rethink, and tend to be committed to a metaphysics that would defend the autonomous selfenclosure of absolute music.

Return to text

41. This scholarship, heavily representing music theorists, includes, for instance, the work of Robert Hatten (1994, 2004), Kofi Agawu (1991, 2000), Byron Almén (2008), David Lidov (2004), Philip Tagg (1987), Eero Tarasti (2001), and Raymond Monelle (1992, 2000, 2006). Hatten, for instance, serves as the series editor for Indiana University Press's "Musical Meaning and Interpretation" series, currently numbering over 30 volumes of monographs, edited volumes, and essay collections. Tarasti presides over the biannual International Congress for Musical Signification. All of the above-listed authors have written extensive technical treatments of music semiotic concepts and general semiotic concepts, far too many to list here.

Return to text

42. Sartre's (1988) work on written language presumes a similar ordering. He asks of writer first: "What aspect of the world do you want to disclose?" and then (only afterwards): "What change do you want to bring into the world by this disclosure?" (37). Sartre implies a model in which utterance is born as a fundamentally disclosive entity, entering into contact with context and social praxis only afterwards. This ordering fails to acknowledge that disclosure, whether through music or language, can never occur or originate from outside of context.

Return to text

43. Meyer, though certainly not broadly representative of current thinking, remains of particular interest because of his commitments to American pragmatist philosophers, including the work of George Herbert Mead, John Dewey, and especially Charles Sanders Peirce. His notion of the "triadic relationship" between musical entity, that to which the entity points, and the enculturated listener calls to mind a Peircean semiotic structure involving sign, object, and interpretant (thinking, expectation, or behavior that arises in the face of the sign-object relation). In this way, he prefigures the contributions of music theorists such as Naomi Cumming (2001), who develops Peirce's difficult body of writings towards insight into musical meaning and the construction of personal 
selves and other selves we impute to situations of music making. Peircean semiotics, emphasizing the particularities of sign use and the forms of action it is imbricated with, is highly consistent with Austin's contribution and its perspective on language meaning. As ethnomusicologist Thomas Turino explains: "From a Peircean perspective: (1) every musical sound, performance or dance movement, and contextual feature that affects an actual perceiver is a sign, and (2) every perceiver is affected by signs in relation to his or her own personal history of experience, which is at once a partially unique but largely shared social experience" $(2014,188)$.

Return to text

44. See especially, Lewin 1987, 175-92). Lewin's shift from intervallic thinking towards what he calls the "transformational attitude" possesses certain affinities with Austin's shift away from constative thinking towards performative analysis of utterance. In the "transformational attitude," the idea of analyzing as though one were inside the music, performing actions and making "moves" in an abstract space implicates a sort of experiential analysis that embeds the analyst as a responsible party with bodily stakes in the production of music analysis. Similarly, Austin's concept of linguistic performativity implicates existential considerations in that it is concerned with the relations between users of language, language's effects, and the overall context of utterance, opening the analysis of language to questions of responsibility for speech-acts and bodily stakes of the production of linguistic effects. Both suggest the fecundity of a thinking rooted less in a notion of fixed and transparent objects, and more in a generative and creative notion of action. I thank Amy Bauer for suggesting this connection to me.

Return to text

45. Cf. Tambiah (1968). Other foundational studies originating in social scientific research on entailing and efficacious aspects of human communication - called the "ethnography of speaking" -include Finnegan (1969), Goffman (1981), Gumperz (1982), and Rosaldo (1982). Musical writers who engage in ethnographies with similar conceptual commitments to the actions and effects produced in and through musical utterance include Kubicki (1999) and Tomlinson (2007).

Return to text

46. In this connection, Lucier's piece is suggestive of some of the Greek musical sources - e.g., Plato, Pseudo-Plutarch, Aristoxenus of Tarentum - that discuss it in terms of various healing (or afflicting) powers (see Zhmud 2012).

Return to text

47. Since the semantic status of musical units is considerably less secure and open to contestation, the use-based theory of musical meaning as illocutionary act-potential is arguably even better suited to understanding music as utterance than it is for linguistic utterance.

Return to text

48. As an exploration of work-ontology, Die Zwei brings to mind as an intertext Jorge Luis Borges's short story "Pierre Menard, Author of the Quixote," in which a narrator describes a fictional symbolist author who sets out to "produce a number of pages which coincided - word for word, and line by line-with those of Miguel de Cervantes" $(1999,91)$. Borges invites the reader to imagine what it would mean for this task to be more than mere copying, and to imagine this identical Quixote as an independent work.

Return to text

49. Kyle Adams invokes Austin's recognition of "saying something" as the "doing of something" to argue that remixes, mashups, and sampling practices perform political acts of resistance to the exercise of capitalist logics over commercial musical production: "The very act of reproducing the work of another artist, let alone reshaping and reconfiguring it, can be seen as a form of resistance against those who control the original artwork, especially when 'those in control' are perceived not to be the artists who created it, but the faceless corporations that claim ownership over it" (2015, 13).

Return to text 
50. On this point, it seems apposite to note that assigning to Die Zwei the status of plagiarism in a debunking or unmasking gesture, is not so much incorrect as it is unproductive. This characterization of the piece closes more doors than it opens because as soon as it is described as plagiarism, a moral claim has been made, one which leads more easily to a dismissal of the piece than to an appreciation of its thought experiment and its challenge to ingrained intuitions concerning the work-concept. Regarding mashups, David Gunkel writes: "Instead of being simply reducible to or comprehended by the ... privileging of originality and authenticity, the mash-up deliberately involves itself in and toys with derivation, plagiarism, inauthenticity, promiscuity, repetition - things that from the [orthodox] perspective can only appear to be negative, monstrous, deficient, and perverse" $(2008,503)$.

Return to text

51. See Kane 2014 and Chion 1994 for discussions of acousmatic (heard, but unseen) sound sources and the history of their associations with supernatural qualities, especially in film sound/music.

Return to text

52. In this connection, there is a small but fascinating corpus of linguistic work on spells, hexes, and curses used in (historical and fictional) witchcraft as illocutionary acts. See, for instance, Culpeper and Semino 2000, and Cornfeld 2012.

Return to text

53. Gilles Deleuze argues in Bergsonism that "virtual" is not opposed to "real, but to "actual," whereby both actual entities and virtual ones stand as real, but have different modes of existence (1988, 96-97).

Return to text

54. Emphasis in the original. Derrida asks of the Declaration: "Is it that the good people have already freed themselves and are only stating the fact of this emancipation in the Declaration? Or is it rather that they free themselves at the instant of and by the signature of this Declaration?" (1986, 9).

Return to text

55. I would add the proviso that it is most useful to think of tools and equipment outside of their possible and common connotations of brutally unsentimental efficiency, cold purposiveness, or capitalistic conversions of the world (or of music) into material for consumption.

Return to text

\section{Copyright Statement}

Copyright $(2019$ by the Society for Music Theory. All rights reserved.

[1] Copyrights for individual items published in Music Theory Online (MTO) are held by their authors. Items appearing in MTO may be saved and stored in electronic or paper form, and may be shared among individuals for purposes of scholarly research or discussion, but may not be republished in any form, electronic or print, without prior, written permission from the author(s), and advance notification of the editors of MTO.

[2] Any redistributed form of items published in MTO must include the following information in a form appropriate to the medium in which the items are to appear:

This item appeared in Music Theory Online in [VOLUME \#, ISSUE \#] on [DAY/MONTH/YEAR]. It was authored by [FULL NAME, EMAIL ADDRESS], with whose written permission it is reprinted here.

[3] Libraries may archive issues of MTO in electronic or paper form for public access so long as each issue is stored in its entirety, and no access fee is charged. Exceptions to these requirements must be approved in writing by the editors of $M T O$, who will act in accordance with the decisions of the Society for Music Theory.

This document and all portions thereof are protected by U.S. and international copyright laws. Material contained herein may be copied and/or distributed for research purposes only. 
